\title{
8. What are the factors determining Indigenous labour market outcomes?
}

\author{
Prem Thapa, Qasim Shah and Shafiq Ahmad
}

The aggregate gaps in employment rates and other labour market outcomes between the non-Indigenous and Indigenous sub-populations in Australia are well documented and form a key plank in the Closing the Gap agenda adopted by the Council of Australian Governments (COAG). Successful employment outcomes with well-paying jobs are critical components of Indigenous wellbeing.

Behind these aggregate gaps however lies a wide variation in the labour market engagement and outcomes for Indigenous Australians. What is less well understood are the various drivers of successful labour market outcomes within the Indigenous sub-population that lead to the aggregate gaps. This occurs because the national surveys on employment and earnings conducted regularly by the Australian Bureau of Statistics (ABS) do not have a sufficiently large sample of Indigenous persons to reliably analyse the underlying determinants of Indigenous employment.

While there is a large literature that looks at labour market outcomes for Indigenous persons, this has focused mainly on analyses of the census data (i.e. Biddle and Yap 2010; Daly 1995; Hunter 2004). While providing valuable insights, the range of explanatory variables available in the census is limited, and also the full extent of different employment status is not regularly recorded. ${ }^{1}$ In this context the periodic National Aboriginal and Torres Strait Islander Social Survey (NATSISS) carried out with a large representative sample of Indigenous households fills a vital gap. It provides the scope for taking a much broader approach to understanding the complex inter-linkages between Indigenous labour market engagement and the other wider dimensions of Indigenous disadvantage.

In this chapter we utilise the full extent of the 2008 NATSISS data to model in detail the determinants of the various components of the labour market status of Indigenous working-age men and women. A specific interest is to analyse how educational attainments affect the employment of Indigenous Australians and whether this relationship is any different from what is found for the general Australian population.

A key related research question is to identify the factors that have driven the changes in Indigenous employment between 2002 and 2008, and to assess the

1 For instance, participants in the Community Development Employment Program (CDEP) are not reliably identified in all censuses because some of the census forms used in specific areas of Australia do not include CDEP employment as a separate category (Gray and Chapman 2006). 
contribution of increasing educational attainment. Unfortunately, because of the rules about how the NATSISS data can be accessed via the Remote Access Data Laboratory (RADL) of the ABS, estimations cannot be done combining the sample data for 2002 and 2008 to directly test changes in the effects of variables such as education over time. We analyse the effects of increasing educational status of Indigenous Australians on their employment status in a simpler way by comparing our estimation results from the 2008 NATSISS with previous results based on analyses of the 2002 NATSISS.

We had a related interest to model the returns to education for Indigenous workers in terms of its effects on increased hourly wages, and to assess whether the returns to education vary according other factors, such as remote location and gender. But this aspect has been left for further research given the difficulty encountered in deriving reliable measures of hourly wages for a large enough sample of Indigenous workers with the variables available in the 2008 NATSISS via RADL. ${ }^{2}$

In analysing the determinants of Indigenous labour force status we specify a categorical model that distinguishes four different labour market outcomes: (a) not in the labour force (NILF), (b) unemployed, (c) participating in the Community Development Employment Program (CDEP) and (d) regular employment. ${ }^{3}$ Given the unique features of the CDEP program, its heavy concentration in remote areas, and the potential differences in motivations for persons wanting to participate in CDEP instead of regular employment, it is necessary to distinguish between CDEP and regular employment. Also, it is important to distinguish the not in labour force category from the unemployed because a distinctive feature of Indigenous labour force status is that a high proportion of Indigenous men are classified as being NILF compared to the general Australian population of working-age men.

In what follows in this chapter, the next section briefly summarises the data from the 2008 NATSISS on labour force status for working-age Indigenous persons by selected characteristics, and compares it with results from the previous NATSISS for 2002, highlighting what have been the major changes that have occurred in this period. We then present the estimation results for the multinomial logit regressions for the determinants of employment status in the 2008 NATSISS, using a standard model specification with conventional personal characteristics and locational indicators as the set of explanatory variables. Our results are compared with a previous study carried out by Stephens (2010a) that estimated a similar model for the 2002 NATSISS. We specifically look at the effects of education, represented with five different categorical educational level variables, on the probability of being in the various labour market status categories separately for men and women.

2 The data reported for both earnings and hours of work (necessary to compute hourly wages) are categorical, and earnings data are not clearly distinguished from other sources of income.

3 Note that in this chapter we use the term 'regular employment' to mean non-CDEP employment. It should not be taken as a description of the permanence or regularity of a job. 
The following section presents additional results for the standard model which is now estimated separately for working-age men and women in remote and non-remote locations. The expanded confidentialised unit record file (CURF) data from the 2008 NATSISS unfortunately has a limited regional classification structure that only distinguishes either State/Territory of residence or remote and non-remote locations, without these two classifications being overlayed. ${ }^{4}$ We chose to work with the remote and non-remote dimension because there are only a few studies (i.e. Stephens 2010a) that have looked at the determinants of Indigenous employment status specifically in remote Australia, and compared how this may differ from other regions. Estimation of separate models for remote and non-remote locations allows us to test whether the explanatory variables can have different effects in these locations, compared to an aggregated model that usually only has a level effect of remote location specified as dummy variable without a full set of interaction terms. ${ }^{5}$ The final section concludes and draws some implications for further research.

\section{Summarising the 2008 and 2002 labour force status outcomes}

Table 8.1 summarises the proportion of the Indigenous population of working age (15-64) by labour force status in both the 2008 and 2002 NATSISS data. The results are tabulated separately for men and women by selected characteristics (age, education and location) and represents weighted estimates. The aggregate results for men and women are quite different in 2008 compared to 2002, with large increases in the proportion employed in regular jobs and corresponding large falls in the proportion participating in CDEP. In the total Indigenous population of working-age men and women, the CDEP participation rate has fallen from 12.7 per cent in 2002 to 5.6 per cent in 2008. The estimated total number of working-age Indigenous persons engaged in CDEP in 2008, based on the NATSISS sampling framework, reduced by more than one-half from 38800 in 2002 to 17600 in 2008. These NATSISS based estimates of the total number of CDEP participants are consistent with the administrative data on CDEP participants that show a decline from around 35000 individuals in 2002-03 to 18800 in June $2008 .^{6}$

\footnotetext{
4 The regional dimensions available on the RADL version of the 2008 NATSISS are even more limited than what was available for the 2002 NATSISS. Several commentators (i.e. Biddle and Hunter 2006) have pointed out the weakness with the 2002 classifications with a plea for more rather than less regional disaggregation to get the most value out of the infrequently collected NATSISS data.

5 This is one key difference between our analyses and a recent contribution from the Productivity Commission that analysed factors influencing Indigenous labour market outcomes with the 2008 NATSISS, using an aggregate model with a remote area dummy variable as one of the explanatory factors (Savvas, Boulton and Jepsen 2011).

6 Refer to the Steering Committee for the Review of Government Service Provision (SCRGSP) 2011: p. 4.86, for the irregular time series administrative data on the total number of CDEP participants.
} 


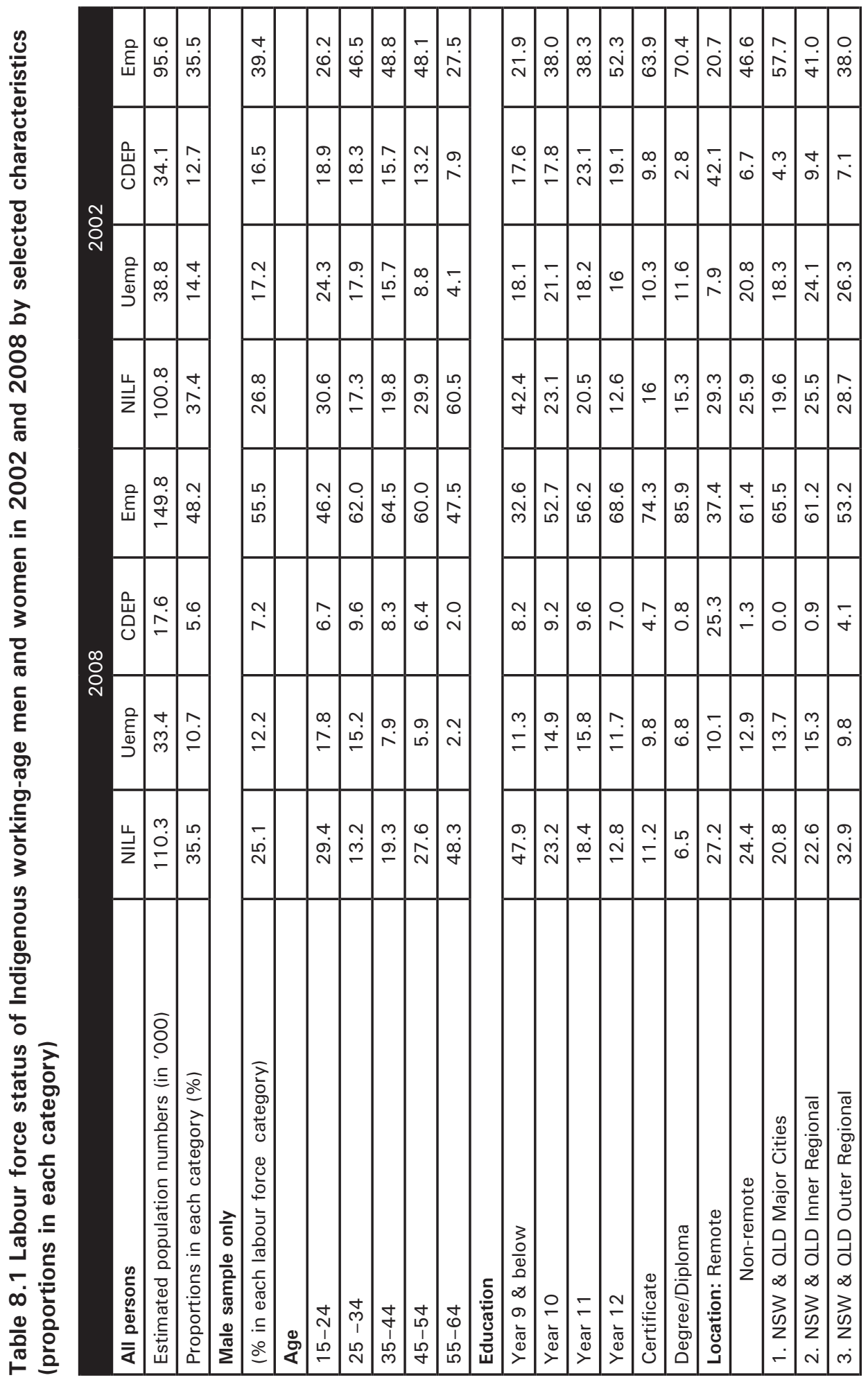




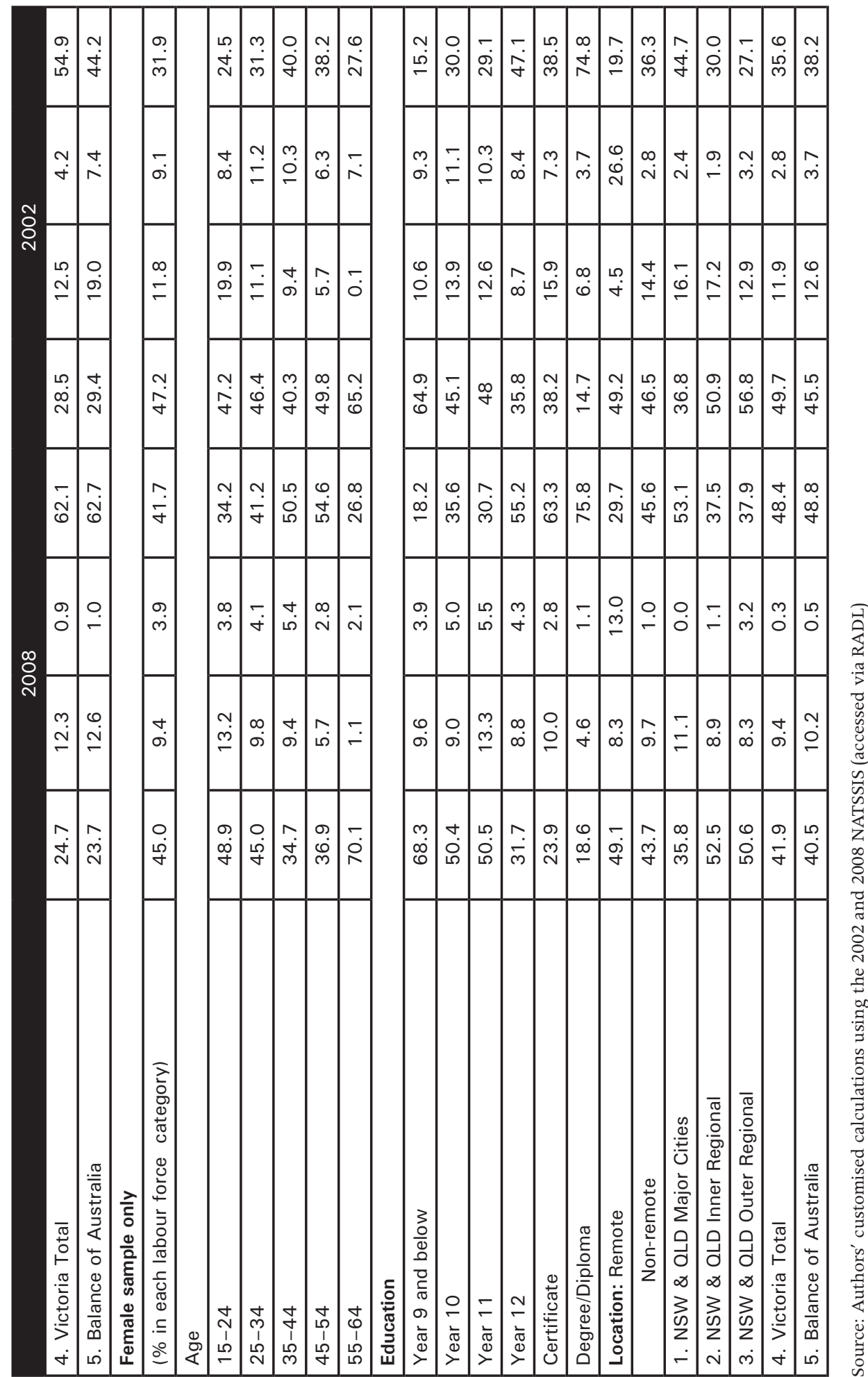


One should note that the decline in the proportion of working-age Indigenous persons participating in CDEP noted in the 2008 NATSISS estimates pre-dates the major changes made to the CDEP program from 1 July 2009. This included the termination of CDEP program in many locations with established economies where Job Services Australia became the main provider of employment services for Indigenous people. ${ }^{7}$ Thus, the increase in non-CDEP employment and corresponding decline in CDEP employment observed in the 2008 NATSISS (which conducted survey interviews between August 2008 and April 2009) is quite independent of the subsequent changes to the CDEP program that took effect from 1 July 2009. ${ }^{8}$ In the absence of panel data, it is not feasible to verify what proportion of those who were previously employed in CDEP in 2002 were employed in non-CDEP jobs by 2008. But given the large increase in nonCDEP employment observed in 2008, this is a likely pathway (in addition to the unemployed and NILF persons also moving into regular employment).

The estimated total number of working-age Indigenous persons with a regular job increased to almost 150000 in 2008, compared to 95600 in 2002.

Excluding CDEP, about 55 per cent of working-age men reported regular employment in 2008 compared to 39 per cent in 2002. Including CDEP, the increase in the employment ratio is more subdued, from about 56 per cent in 2002 to 63 per cent in 2008. The proportion of working-age males who are classified as unemployed also declined to 12.2 per cent in 2008 from 17.2 per cent in $2002 .^{9}$

The increase in the proportion of working-age women who are employed in a regular job was more modest between 2002 (31.9\%) and 2008 (41.7\%). Almost 55 per cent of working-age women are either unemployed or NILF.

The further disaggregation of the employment status in 2008 of working-age Indigenous men and women by age, education and location reveal expected patterns. The age profile of being in regular employment is particularly strong for

\footnotetext{
7 Also new CDEP participants from 1 July 2009 in all locations had to apply for regular income support payments from Centrelink. CDEP participants who were receiving CDEP wages at 30 June 2009 can continue receiving CDEP wages until June 2017, as long as they remain eligible. The continuation of CDEP wages to June 2017 is a part of the new Remote Jobs and Communities Program that will come into operaton from July 2013.

8 There were ongoing changes to the CDEP program even before the major reforms that became effective from 1 July 2009. The July 2009 changes had also been foreshadowed early in a government discussion paper released in May 2008. So some of the changes in CDEP employment observed in the 2008 NATSISS could be partially policy induced, in response to the anticipation of the changes that took effect from 1 July 2009.

9 These unemployed percentages are not to be confused with the working-age male unemployment rate for which the number of unemployed persons is represented as a proportion of the labour force, and not the total population, as we have reported in Table 8.1. It is a straightforward adjustment to obtain the unemployment rate from the unemployed proportion in Table 8.1, by dividing by the proportion by the labour force to population ratio for each category.
} 
males where around 62 per cent of men aged 35-44 report regular employment, compared to 38 per cent in the youngest (15-24) age group, and 34 per cent in the oldest (55-64) working-age group.

The gain in regular employment between 2002 and 2008 has occurred across all age groups for men, and for all but one age group for women (the 55-64 year olds being the exception), as shown in Fig. 8.1. Some of these gains for specific age groups are quite large, with the proportion employed in a regular job for young males in the 15-24 age group and older males in the 55-64 age group both increasing by 20 percentage points from 2002 to 2008.

Fig. 8.1 Proportion employed (excluding CDEP) by age group, Australia, 2002 and 2008



Source: Table 8.1 , this chapter

Higher levels of education lead to a continuous increase in the employment ratio for men, which doubles from 36 per cent for those with a Year 9 or lower level of schooling to 73 per cent for those with a degree or diploma. The NILF category also falls consistently for men with higher levels of education. The age profile differences for working-age women are more muted, with the highest employment ratio (of 48\%) observed for 35-45 year olds. Education has an even stronger effect for women with the proportion in regular employment increasing dramatically from a low of 23 per cent for those with Year 9 or lower schooling to 78 per cent for those with a degree or diploma. 
Fig. 8.2 Proportion employed (excluding CDEP) by education, Australia, 2002 and 2008

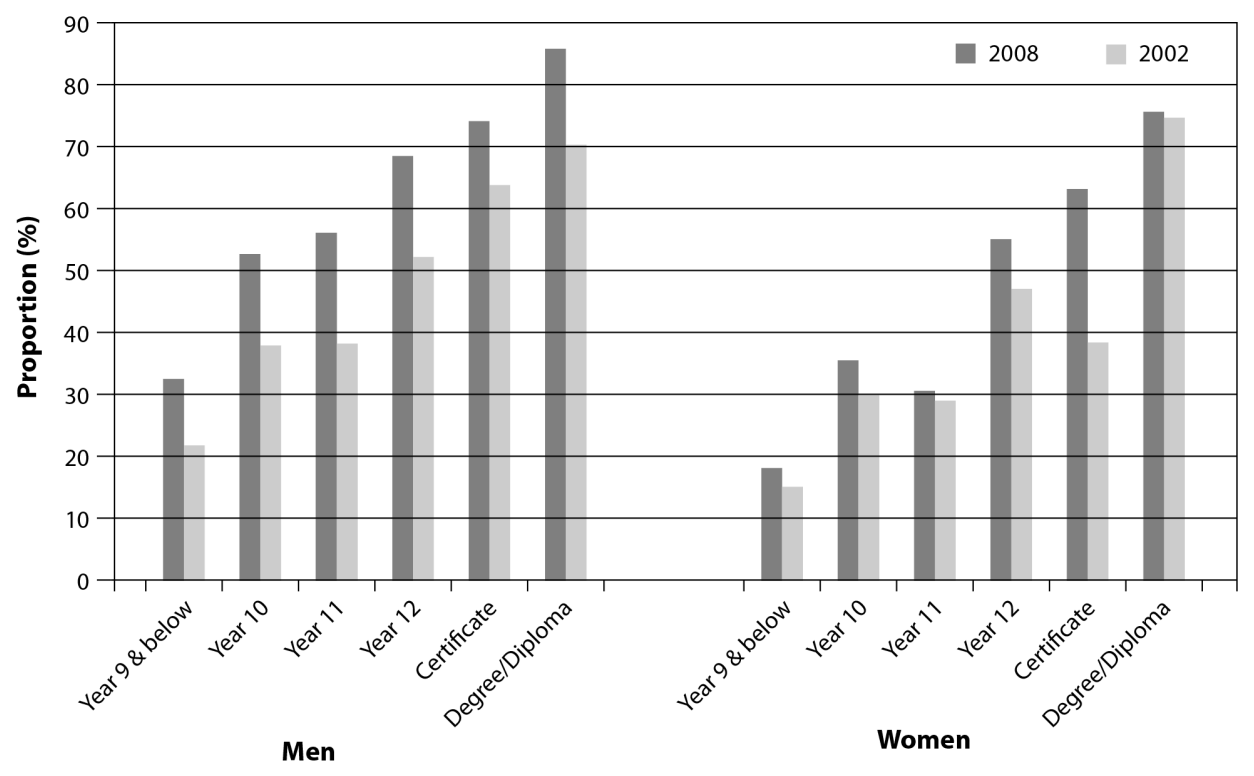

Source: Table 8.1

The consistent increases in the proportion of men employed for each education category between 2002 and 2008 is again shown in Fig. 8.2. There have been some strong gains even at the lowest levels of education - Year 9 or below, and Year 10. The pattern in changes between 2002 and 2008 is slightly different for women. There are only modest increases in the proportion employed (excluding CDEP) at low levels of education. Surprisingly, there is also no increase in employment at the highest level of education for women (with a Degree/ Diploma). This result could possibly be due to the fact that the proportion of women employed in this category is already high (over 70\% in 2002) and near universal employment is uncommon for all women. But it can also indicate a differential impact of education on employment status for men and women over time, perhaps reflecting differences in the mix of degrees and diplomas between men and women.

The increase between 2002 and 2008 in the proportion of working-age Indigenous men and women who have a regular job has occurred more or less evenly between remote and non-remote locations. For men this proportion increased by about 15-16 percentage points in both locations between 2002 and 2008. For women the increase in the proportion with regular jobs was about 10 percentage points in both remote and non-remote locations. This however means that the large gaps in the proportions who are regularly employed between 
remote and non-remote locations still persist. For instance, only 37.4 per cent of Indigenous working-age men in remote locations were in regular employment in 2008, compared to 61.4 per cent in non-remote locations.

Including CDEP participation in employment, the gap between remote and nonremote employment proportions disappears for men, but still persists at around 4 percentage points lower employment for women in remote areas.

Fig. 8.3 shows the change in employment patterns in remote locations only, but including changes in CDEP participation. This presents a more sobering perspective - that the large gains in the proportion with regular jobs have been more or less counter-balanced by the fall in CDEP participation. For men, the combined proportion with a regular or CDEP job is more or less unchanged between 2002 and 2008 (though of course it will usually be more advantageous to have a regular job than be a CDEP participant). But women in remote locations have gone backwards on this combined indicator, which has fallen from 46.3 per cent in 2002 to 42.7 per cent in 2008. For women in remote Australia, although there has been a large gain in the proportion with regular jobs, the fall in CDEP participation has been even larger than the increase in regular employment.

When the non-remote locations are further broken down into major cities and inner and outer regional areas, as specified in Table 8.1, the employment ratio is highest in the major cities of New South Wales and Queensland for both men and women. For men there is a small dip in the employment ratio for the outer regional areas of New South Wales and Queensland, but in all other nonremote locations the employment rate for working-age Indigenous men is more than 60 per cent. Also more than 53 per cent of working-age women in the major cities of New South Wales and Queensland are in regular employment. This is an indication that even by 2008 (before the termination of CDEP in non-remote locations) non-CDEP employment was being established as a social norm for Indigenous working-age persons in the main urban and inner regional population centres. This developing social norm of being in regular employment is even stronger when comparing Indigenous employment outcomes between 1994 and 2008, as Gray and Hunter (2011) have noted. 
Fig. 8.3 Remote locations: Proportion employed and in CDEP, Australia, 2002 and 2008

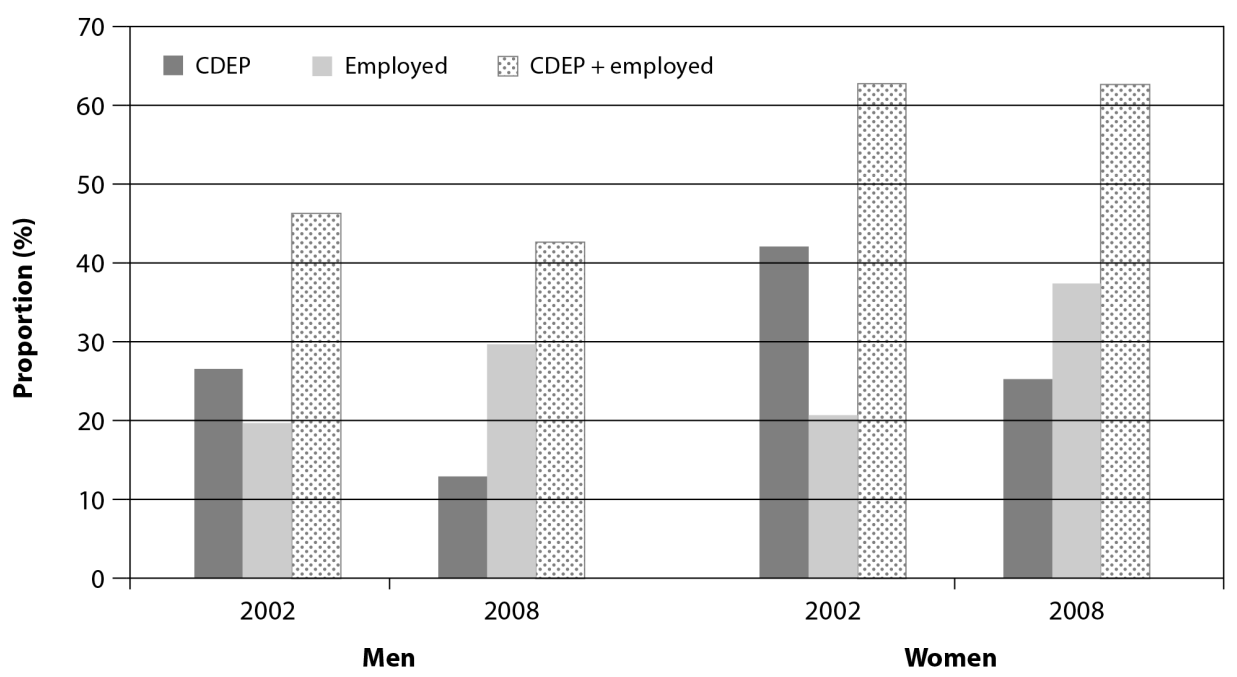

Source: Table 8.1

\section{Factors affecting Indigenous labour market status}

In this section we report the results for the multinomial logit regressions for employment status where four status categories are distinguished:

1. not in the labour force (NILF)

2. unemployed (using standard ABS definitions)

3. CDEP employment participation

4. regular employment (non-CDEP).

The multinomial logit regression model is a standard approach to estimating labour force status when there are more than two categorical outcomes identified that are not ranked or ordered. In our model specification we follow closely the model and variable definitions used by Stephens (2010a) to estimate labour force status from the previous 2002 NATSISS in order to assess changes over time. Like Stephens we specify the NILF category as the base category and estimate logit coefficients for the other three labour force categories, relative to the base category. We differ slightly in our model specification because we ignore the 'Housing' subset of variables used by Stephens because these variables, such as having structural problems or not being able to carry out repairs, are not likely 
to be independent determinants of labour force status. The choice of housing tenure and the quality of housing stock that Indigenous persons live in are more likely to be the consequences of their employment status and income levels.

In this section we report on the multinomial logit regressions results which are estimated separately for men and women but have a combined sample of the remote and non-remote locations, with only a dummy variable indicator used to identify the effect of remote locations. We present two different sets of results for each model: the estimated odds ratios are reported in Tables 8.2 and 8.3, for men and women, respectively; and Appendix 8A Tables A8.2 and A8.3 present the corresponding marginal effects on the probability of being in each labour force category.

Table 8.2 Multinomial logit regression estimates on the determinants of labour force status for Indigenous working-age men ${ }^{\text {a }}$ (odds ratios)

\begin{tabular}{|c|c|c|c|c|c|c|c|c|c|}
\hline \multirow[b]{2}{*}{ NILF is the base outcome } & \multicolumn{3}{|c|}{ Uemp } & \multicolumn{3}{|c|}{ CDEP } & \multicolumn{3}{|c|}{ Emp } \\
\hline & $\begin{array}{l}\text { odds } \\
\text { ratio }\end{array}$ & & $\begin{array}{l}\text { std. } \\
\text { error }\end{array}$ & $\begin{array}{l}\text { odds } \\
\text { ratio }\end{array}$ & & $\begin{array}{l}\text { std. } \\
\text { error }\end{array}$ & $\begin{array}{l}\text { odds } \\
\text { ratio }\end{array}$ & & $\begin{array}{l}\text { std. } \\
\text { error }\end{array}$ \\
\hline Remote & 0.75 & & 0.20 & 9.39 & ** & 3.70 & 0.86 & & 0.19 \\
\hline Age & & & & & & & & & \\
\hline $25-34$ & 0.92 & & 0.27 & 0.74 & & 0.25 & 1.30 & & 0.34 \\
\hline $35-44$ & 0.36 & $* *$ & 0.12 & 0.65 & & 0.25 & 1.03 & & 0.30 \\
\hline $45-54$ & 0.25 & $* *$ & 0.11 & 0.53 & & 0.22 & 0.98 & & 0.29 \\
\hline $55-64$ & 0.06 & $* *$ & 0.03 & 0.11 & $* *$ & 0.06 & 0.50 & * & 0.16 \\
\hline Married & 1.42 & & 0.34 & 1.72 & $*$ & 0.46 & 2.69 & ** & 0.52 \\
\hline Number of dependents & & & & & & & & & \\
\hline 1 & 0.66 & & 0.20 & 1.09 & & 0.42 & 0.85 & & 0.18 \\
\hline $2-3$ & 0.68 & & 0.20 & 0.95 & & 0.29 & 0.67 & & 0.17 \\
\hline $4 \&$ above & 0.95 & & 0.39 & 0.52 & & 0.22 & 0.53 & & 0.18 \\
\hline Education & & & & & & & & & \\
\hline Year 9 or below & 0.55 & * & 0.16 & 0.55 & & 0.17 & 0.52 & $* *$ & 0.12 \\
\hline Year 11 & 1.70 & & 0.67 & 1.73 & & 0.75 & 2.17 & $*$ & 0.74 \\
\hline Year 12 & 1.29 & & 0.51 & 1.24 & & 0.47 & 2.31 & $* *$ & 0.69 \\
\hline Certificate & 2.27 & * & 0.85 & 1.73 & & 0.68 & 3.55 & $* *$ & 1.01 \\
\hline Degree/Diploma & 3.01 & & 1.76 & 0.62 & & 0.47 & 5.77 & $* *$ & 2.44 \\
\hline $\begin{array}{l}\text { Difficulty in English } \\
\text { speaking }\end{array}$ & 0.22 & $* *$ & 0.12 & 0.63 & & 0.25 & 0.60 & & 0.27 \\
\hline Self-assessed health status & & & & & & & & & \\
\hline Good & 0.85 & & 0.22 & 0.65 & & 0.18 & 0.65 & $*$ & 0.13 \\
\hline Fair & 0.64 & & 0.19 & 0.26 & $* *$ & 0.10 & 0.28 & $* *$ & 0.07 \\
\hline Poor & 0.37 & * & 0.17 & 0.28 & $* *$ & 0.13 & 0.06 & $* *$ & 0.02 \\
\hline
\end{tabular}


Survey Analysis for Indigenous Policy in Australia

\begin{tabular}{|c|c|c|c|c|c|c|c|c|c|}
\hline \multirow[b]{2}{*}{ NILF is the base outcome } & \multicolumn{3}{|c|}{ Uemp } & \multicolumn{3}{|c|}{ CDEP } & \multicolumn{3}{|c|}{ Emp } \\
\hline & $\begin{array}{l}\text { odds } \\
\text { ratio }\end{array}$ & & $\begin{array}{l}\text { std. } \\
\text { error }\end{array}$ & $\begin{array}{l}\text { odds } \\
\text { ratio }\end{array}$ & & $\begin{array}{l}\text { std. } \\
\text { error }\end{array}$ & $\begin{array}{l}\text { odds } \\
\text { ratio }\end{array}$ & & $\begin{array}{l}\text { std. } \\
\text { error }\end{array}$ \\
\hline Has disability & 0.41 & ** & 0.10 & 0.55 & * & 0.14 & 0.48 & ** & 0.09 \\
\hline Live in homelands & 0.84 & & 0.21 & 1.05 & & 0.25 & 0.69 & & 0.14 \\
\hline Mixed household & 0.77 & & 0.20 & 0.24 & ** & 0.12 & 1.36 & & 0.28 \\
\hline Attends cultural events & 1.04 & & 0.25 & 1.99 & * & 0.65 & 1.20 & & 0.23 \\
\hline $\begin{array}{l}\text { Indigenous language at } \\
\text { home }\end{array}$ & 0.96 & & 0.36 & 1.11 & & 0.34 & 0.37 & * * & 0.11 \\
\hline $\begin{array}{l}\text { Removed from natural } \\
\text { family }\end{array}$ & 1.09 & & 0.33 & 0.71 & & 0.29 & 0.48 & * & 0.14 \\
\hline $\begin{array}{l}\text { Queensland only: Torres } \\
\text { Strait Islanders }\end{array}$ & 1.31 & & 0.89 & 1.51 & & 0.79 & 2.74 & & 1.47 \\
\hline Arrested in last 5 years & 1.87 & ** & 0.43 & 1.44 & & 0.37 & 0.65 & * & 0.13 \\
\hline
\end{tabular}

Sample N for regression $=2722$, Psuedo $\mathrm{R}^{2}=0.27$

a. These estimated odds ratios are relative to being NILF.

${ }^{*}$ and ${ }^{* *}$ indicate statistical significance at $5 \%$ and $1 \%$ respectively.

Source: Authors' customised calculations using the 2008 NATSSIS (accessed via RADL)

Table 8.3 Multinomial logit regression estimates on the determinants of labour force status for Indigenous working-age women ${ }^{\text {a }}$ (odds ratios)

\begin{tabular}{|c|c|c|c|c|c|c|c|c|c|}
\hline \multirow[b]{2}{*}{ NILF is the base outcome } & \multicolumn{3}{|c|}{ Uemp } & \multicolumn{3}{|c|}{ CDEP } & \multicolumn{3}{|c|}{ Emp } \\
\hline & $\begin{array}{l}\text { odds } \\
\text { ratio }\end{array}$ & & $\begin{array}{l}\text { std. } \\
\text { error }\end{array}$ & $\begin{array}{l}\text { odds } \\
\text { ratio }\end{array}$ & & $\begin{array}{l}\text { std. } \\
\text { error }\end{array}$ & $\begin{array}{l}\text { odds } \\
\text { ratio }\end{array}$ & & $\begin{array}{l}\text { std. } \\
\text { error }\end{array}$ \\
\hline Remote & 0.83 & & 0.16 & 7.27 & $* *$ & 2.44 & 1.17 & & 0.16 \\
\hline Age & & & & & & & & & \\
\hline $25-34$ & 1.00 & & 0.23 & 0.75 & & 0.23 & 1.78 & & 0.37 \\
\hline $35-44$ & 0.92 & & 0.23 & 1.76 & & 0.57 & 2.35 & ** & 0.49 \\
\hline $45-54$ & 0.59 & & 0.21 & 0.96 & & 0.34 & 2.59 & * * & 0.59 \\
\hline $55-64$ & 0.05 & $* *$ & 0.02 & 0.39 & * & 0.16 & 0.57 & * & 0.15 \\
\hline Married & 0.64 & $*$ & 0.13 & 1.11 & & 0.26 & 0.90 & & 0.13 \\
\hline Number of dependents & & & & & & & & & \\
\hline 1 & 0.63 & & 0.17 & 0.71 & & 0.26 & 0.49 & * * & 0.09 \\
\hline $2-3$ & 0.42 & ** & 0.11 & 0.58 & & 0.18 & 0.37 & * * & 0.06 \\
\hline 4 \& above & 0.34 & $* *$ & 0.10 & 0.43 & * & 0.15 & 0.15 & $* *$ & 0.03 \\
\hline Education & & & & & & & & & \\
\hline Year 9 or below & 0.64 & & 0.16 & 0.56 & * & 0.16 & 0.36 & $* *$ & 0.07 \\
\hline Year 11 & 1.36 & & 0.38 & 1.09 & & 0.44 & 0.89 & & 0.17 \\
\hline Year 12 & 1.07 & & 0.34 & 1.19 & & 0.43 & 1.93 & $* *$ & 0.42 \\
\hline Certificate & 2.15 & $* *$ & 0.62 & 2.16 & $*$ & 0.80 & 3.59 & $* *$ & 0.71 \\
\hline Degree/Diploma & 1.47 & & 0.62 & 0.62 & & 0.32 & 4.20 & $* *$ & 1.07 \\
\hline
\end{tabular}




\begin{tabular}{|c|c|c|c|c|c|c|c|c|}
\hline \multirow[b]{2}{*}{ NILF is the base outcome } & \multicolumn{2}{|c|}{ Uemp } & \multicolumn{3}{|c|}{ CDEP } & \multicolumn{3}{|c|}{ Emp } \\
\hline & $\begin{array}{l}\text { odds } \\
\text { ratio }\end{array}$ & $\begin{array}{l}\text { std. } \\
\text { error }\end{array}$ & $\begin{array}{l}\text { odds } \\
\text { ratio }\end{array}$ & & $\begin{array}{l}\text { std. } \\
\text { error }\end{array}$ & $\begin{array}{l}\text { odds } \\
\text { ratio }\end{array}$ & & $\begin{array}{l}\text { std. } \\
\text { error }\end{array}$ \\
\hline $\begin{array}{l}\text { Difficulty in English speaking } \\
\text { Self-assessed health status }\end{array}$ & 1.70 & 0.82 & 0.80 & & 0.32 & 0.84 & & 0.35 \\
\hline Good & 0.87 & 0.18 & 0.93 & & 0.23 & 0.68 & $* *$ & 0.10 \\
\hline Fair & 0.95 & 0.29 & 0.80 & & 0.28 & 0.56 & $* *$ & 0.11 \\
\hline Poor & 0.96 & 0.34 & 0.64 & & 0.44 & 0.24 & $* *$ & 0.08 \\
\hline Has disability & 1.27 & 0.26 & 0.93 & & 0.24 & 0.82 & & 0.11 \\
\hline Live in homelands & 1.14 & 0.23 & 1.66 & * & 0.37 & 0.76 & * & 0.11 \\
\hline Mixed household & 0.76 & 0.17 & 0.55 & & 0.26 & 1.68 & ** & 0.28 \\
\hline Attends cultural events & 1.17 & 0.24 & 1.38 & & 0.41 & 1.37 & * & 0.20 \\
\hline Indigenous language at home & 1.07 & 0.32 & 1.76 & $*$ & 0.44 & 0.84 & & 0.20 \\
\hline Removed from natural family & 1.43 & 0.43 & 0.07 & $* *$ & 0.05 & 0.85 & & 0.23 \\
\hline $\begin{array}{l}\text { Queensland only: Torres State } \\
\text { Islanders }\end{array}$ & 0.76 & 0.43 & 1.43 & & 0.81 & 1.07 & & 0.38 \\
\hline Arrested in last 5 years & 1.08 & 0.25 & 1.50 & & 0.47 & 0.37 & ** & 0.10 \\
\hline
\end{tabular}

Sample N for regression $=3573$, Psuedo $\mathrm{R}^{2}=0.21$

a. These estimated odds ratios are relative to being NILF.

* and ${ }^{* *}$ indicate statistical significance at $5 \%$ and $1 \%$ respectively.

Source: Authors' customised calculations using the 2008 NATSISS (accessed via RADL)

The underlying estimated model is the same in both of these results, but their interpretations are quite different. The odds ratios compare outcomes across the different categories of labour force status, indicating how the probability of being in a particular category - such as being unemployed, or in CDEP or in regular employment - are determined by the explanatory variables, relative to being in the base category of being NILF. On the other hand, the marginal effects measure how a particular variable increases or decreases the probability of being in a specific labour force category, relative to the average probability of being in that particular category. So we can determine the marginal effects of a specific variable for each of the four labour force status categories defined, whereas the odds ratios make sense only for the remaining three categories relative to the nominated base category of being in NILF.

Summary statistics on the entire explanatory variables used in these regressions are presented in Appendix 8A Table A8.1 for men and women separately and in aggregate. The sample consists of 3058 working-age men and 4027 workingage women. The actual estimation sample used for the multinominal logit regressions is slightly smaller because full time students have been excluded and there are some missing values on several variables. 
When the odds ratio estimate for a specific combination of a particular labour force status category and explanatory variable is close to 1 , this means that variable does not have any effect on changing the probability of being in that labour force category, in comparison to being in the base category of NILF. Variables that increase the relative probability (or odds) of being in a specific labour force category (compared to being NILF) will have odds ratios significantly greater than 1. Variables that lower the relative probability of being in that labour force category will have an odds ratio less than 1.

Looking at the results for men in Table 8.2, and focusing on the last column of the odds ratio coefficient estimated for being in regular employment, the odds of being employed are not affected much by age group. Only the highest age group of 45-54 has a significantly lower odds of being employed compared to the reference age group of $15-24 .^{10}$

The educational category effects on being in regular employment are very strong. Compared to the reference case of persons with only Year 10 schooling, the odds of regular employment improves considerably and progressively with higher levels of education. With a Year 12 qualification, men have a 2.3 times higher chance of being employed compared to only Year 10 qualification. With a degree or graduate diploma, this relative advantage increases to 5.8 times higher odds of being employed. Similarly for those with only a Year 9 or lower schooling, the odds of regular employment are about one-half of those who have completed Year 10.

Another variable that increases the odds of regular employment for men is being married.

Variables that significantly reduce the odds of being employed for men are having a disability, having low levels of self-assessed health (compared to being in excellent health), living in their traditional homeland area, speaking an Indigenous language at home, having been removed from their natural family, and also for having been arrested in the past five years. The effect of having been removed is quite strong - the negative effect on the odds of being in regular employment for removed men is equivalent to the effect of having a disability (both have estimated odds ratios of 0.48$).{ }^{11}$

10 The estimation sample excludes all full time students. Many full-time students in the 15-24 age group are likely to be in regular employment. So excluding this category may reduce the age profile on the odds of being employed, compared to a model specification where all persons aged 15-64 are used in the estimation sample irrespective of their student status.

11 The NATSISS asks a very simple question of survey respondents on whether they have ever been removed from their natural family. It does not provide any additional context on why and when the removal happened; but the inference is that this response provides an approximate way to identify the surviving members of the Stolen Generations. Our results show the additional disadvantage they suffer in terms of employment outcomes. 
After having controls for the above variables, being in a remote location by itself does not affect the odds of regular employment relative to being NILF. Unfortunately the RADL version of the 2008 NATSISS data does not permit a further disaggregation into remote and very remote locations. Our results show that the average effect of being in a remote or very remote location is not a statistically significant determinant of the probability of being in regular (non-CDEP) employment. This result does not preclude there being a very different effect of living in very remote locations compared to being in just a remote location. ${ }^{12}$ The fact that some of the other variables which are closely correlated with very remote locations - such as living in a traditional homeland or speaking an Indigenous language - have significant negative effects indicate that they could be acting as proxy variables for living in very remote locations, and having an adverse effect on the probability of regular employment. ${ }^{13}$

No significant effect is also found for living in a mixed Indigenous and nonIndigenous household.

Looking at the results for CDEP participation of Indigenous men (in the second column of Table 8.2) there are clear contrasts with the results for regular employment. Remote location, as expected, is highly correlated with participation in CDEP, with increased odds of more than nine times. Secondly, higher levels of education do not significantly affect the odds of CDEP participation in a consistent manner. Disability, poor health and living in a mixed household significantly reduce the odds of CDEP participation.

The logistic regression results for the determinants of employment status for women, as reported in Table 8.3, in general follows the pattern for men, but with some key differences on specific variables. Considering firstly the column of results for regular employment, being of prime working age and having higher levels of education significantly improve the odds of being in regular

12 ABS unpublished data from the 2008 NATSISS cited in SCRGSP (2011) shows there is a 10 percentage points difference between remote and very remote locations in the regular employment rate of all working age Indigenous persons (men and women). The proportion of the working-age population in regular employment in each of the five detailed Accessibility/Remoteness Index of Australia (ARIA) categories are: $58.6 \%$ in major cities, $49.6 \%$ in inner regional, $48.4 \%$ in outer regional, $39.6 \%$ in remote and $29.3 \%$ in very remote areas (see SCRGSP 2011: Attachment Table 4A.6.15).

13 For instance, there is a clear correlation between living in very remote locations and living in a traditional homeland. In other tabulations of the 2008 NATSISS data reported with the full set of ARIA categories, of the total population that recognises a traditional homeland in very remote locations, more than half $(51 \%)$ of this sub-group actually lives in their homelands. The corresponding proportion is much lower in remote areas at $33 \%$ only (see Table 2.17.3b in AIHW 2011). Given that there is also a higher proportion of persons who recognise a traditional homeland among residents of very remote locations, the relative distribution of persons who live in traditional homelands (excluding non-remote Australia) is heavily skewed towards very remote locations compared to remote locations. Among persons who live in traditional homelands in either remote or very remote locations, almost $72 \%$ are in very remote locations compared to only $18 \%$ in remote locations (derived from AIHW 2011: Table 2.17.3a). Hence it is likely that the significant negative effect of living in a homeland that are reported in Table 8.2 is picking up the extra employment disadvantage of being in very remote locations compared to just a remote location. 
employment. Poor self-assessed health reduces the odds of regular employment, as does having been arrested. Living in a mixed Indigenous and non-Indigenous household increases the likelihood of being in regular employment for womenwhich was not found to be the case for men.

Women also don't get an employment boost from being married, compared to the significantly higher odds for married men being in regular employment. Having a higher number of dependents also significantly reduces the odds of being in regular employment for women.

The logit regression results for the CDEP category of female employment status also differ qualitatively from the corresponding results for men. While remote location has a consistent positive effect on CDEP participation in both cases, several education categories have a significant effect for women only. Having a Certificate qualification more than doubles the odds of CDEP participation for women; and having only Year 9 schooling or less almost halves the odds of CDEP participation. The effect of living in a homeland and speaking an Indigenous language at home both significantly increase the odds for female CDEP participation, while having been removed from family significantly reduces the probability of CDEP participation, which was not the case for men.

The marginal effects of the regression variables on the probability of being in each of the four labour market status categories are presented in Appendix 8A Tables 8A.2 and 8A.3 for men and women, respectively. The marginal effects are computed at the mean of the data. The base case probability noted in the first row under the labour force status column headings of Tables 8A.2 and 8A.3 (and other similar tables) for each labour force category gives the estimated probability of being in that particular category for a specific reference person. ${ }^{14}$ For such a reference male person, the probability of being in regular employment is estimated at 68 per cent (Table 8A.2).

The marginal effects reported for specific variables then measure the additional change (either an increase or decrease) in this base probability when there is a change in a specific characteristic of that reference person. For instance, our reference person is unmarried. If he were to be married (but has all other characteristics unchanged) the estimated marginal effects coefficient for the 'married' variable shows that the probability of regular employment is now increased by 17 percentage points. Similarly, having a degree or diploma

14 The estimated base case probability of employment is for a reference person who lives in a non-remote location, age 15-24, not married, no dependents, Year 10 education, no English difficulty, non-smoker, excellent self-assessed health status, no disability, does not live on homelands, household composition all Indigenous, does not attach importance to attending selected cultural events, no Australian Indigenous languages spoken at home, not removed from natural family, and not arrested in last 5 years. 
compared to Year 9 or below increases the probability of regular employment by 21 percentage points. This is a large effect given that the base probability of being in regular employment is already a very high 68 per cent.

The statistical significance of the estimated marginal effects can differ from the statistical significance of the odds ratios. The former are evaluated for a specific reference person and these changes in probability are non-linear at different data points when there is a change in a specific characteristic for the reference person. But in general we expect consistency in the statistical significance of the results based on the odds ratio and the marginal effects, as is mostly the case in comparing Tables 8A.2 and 8A.3 (marginal effects) with Tables 8.2 and 8.3 (odds ratios).

One divergent result is that for men living in a mixed household there is a significant positive marginal effect but the odds ratio is not significantly higher than 1 in Table 8.2.

The marginal effects coefficients can also be compared across variables since each effect is relative to the base probability. So it is of interest to note from Appendix 8A Table 8A.2 that having been arrested has the same magnitude negative effect on the probability of regular employment for men as having been removed (17 percentage points reduction in both cases).

Looking at the marginal effects for women in Appendix 8A Table 8A.3, there is even more consistency with the odds ratio results of Table 8.3. The only divergent result is that living in a homeland has a significantly negative marginal effect (at the $5 \%$ significance level) while this effect was not significant when measured as an odds ratio in Table 8.3.

The marginal effect of higher education levels on the probability of being in regular employment is even higher for women. A degree or diploma increases this probability by 33 percentage points. For women, the effect of having been arrested is also larger (minus 22 percentage points off a lower base probability than the minus 16 percentage points off a higher base probability for men).

\section{Factors affecting Indigenous labour market status in remote and non-remote locations}

This section presents the results for the multinominal logit models when estimated separately for the remote and non-remote locations. In the previous section the effect of remoteness was restricted to a level effect on the change in the odds ratio or the base probability of being in a specific labour force category, independent of the other variables in the model. For both men and women 
the only consistently significant effect of remote location was found to be an increased probability of being a CDEP participant, with a higher marginal effect observed for men.

Estimation of separate models allows us to test if the effects of other variables in the model are different between remote and non-remote locations. We are particularly interested in the role of education on the probability of being in regular employment.

For brevity only the marginal effects results of the estimated models in this section are presented in Appendix 8A. Appendix 8A Tables 8A.4 and 8A.5 present the marginal effects of the regression variables estimated for non-remote locations, for men and women respectively. Appendix 8A Tables 8A.6 and 8A.7 present the corresponding results for remote locations.

Comparing the non-remote and remote locations results for men (Tables 8A.4 and 8A.6) there are several divergent estimates. Employment is increasing with age in remote locations but is either not significant or decreasing at the highest age group in non-remote locations. The effects of higher levels of education are much stronger in remote locations, with a degree or diploma increasing the probability of regular employment by almost 43 percentage points in remote areas compared to only 15 percentage points in non-remote location (although the underlying base probabilities also differ considerably).

Living in a homeland and speaking an Indigenous language have significant negative effects only in remote locations. As noted in the previous section III, this may again be a proxy for distinguishing the lower levels of regular employment in very remote locations where persons living in a traditional homeland or speaking an Indigenous language are concentrated within our broader definition of remote Australia. Being removed from natural family has no effect in remote locations but has a significant negative effect in non-remote locations. The negative effect of having been arrested is similar in both locations.

For women (comparing Tables 8A.5 and 8A.7) there is more similarity in the significance of results by location than for men. But the magnitudes do vary greatly, particularly for the education variables. While the base probabilities of being in regular employment are similar for women between the two locations, the boost provided by higher levels of education (Certificate and Degree/Diploma) are quite large in remote locations: 34 and 54 percentage points, respectively, compared to 26 and 29 percentage points in non-remote locations. The effects of age groups are similar with a higher probability of regular employment in the 35-44 and 45-54 age groups. Being married has no effect on this probability in 
both locations. There also are consistent positive marginal effects for living in a mixed household and a consistent negative effect of having been arrested in both locations.

Finally in Table 8.4 in the main text we present a comparison of our key results on the marginal effects of higher levels of education by location with the corresponding results obtained by Stephens (2010a) with the 2002 NATSISS data for remote and non-remote locations. The top panel of Table 8.4 summarises the 2008 computations of the marginal effects of education which are the same as the detailed results in Appendix 8A Tables 8A.4 to 8A.7. The bottom panel of Table 8.4 presents the marginal effects of education estimated by Stephens with the 2002 NATSISS data.

Though there is a degree of similarity in the magnitude of these marginal effects, looking at the effects on the probability of regular employment in the last set of columns by location, the difference between remote and non-remote locations appear to be narrower in 2002 than in our 2008 results.

For instance, in 2002 the estimated marginal effect of a degree or diploma for men was about 12 percentage points in non-remote and 9 percentage points in remote locations. But in 2008 the corresponding ratios are wider apart - 15 percentage points in non-remote and a much bigger 43 percentage points in remote locations. There is a similar widening of gaps in the marginal effects of a degree or diploma on a women's probability of being in regular employment. In our 2008 computations, the estimated marginal effect in remote locations is almost double that in non-remote areas (0.54 versus 0.29$)$; while in 2002 the relativity was much smaller (0.59 and 0.45$)$.

Unfortunately the way the NATSISS survey data is made available by ABS on RADL does not permit a direct test of the possibly widening gaps in the marginal effects of higher education between remote and non-remote locations between 2002 and 2008. These two data sets cannot be combined to estimate a joint model with the combined data set with varying coefficients for 2002 and 2008 that can be tested for statistically significant differences. But our simple comparisons in Table 8.4 do point to such a widening gap and this merits further investigation.

This issue can be analysed in a broader context of why and how the returns to Indigenous education, and particularly the highest levels of education, can differ across regions and what might be the mechanisms that lead to this difference. This needs more structured analyses, allowing for persons to be mobile across regions in response to better employment and earning opportunities, and distinguishing the effects of differing personal characteristics across regions from the pure regional effects. Unfortunately, despite the many strengths of the NATSISS, it is not the panel data on Indigenous employment choices that is best suited for the detailed analyses required to unpack these different effects. 


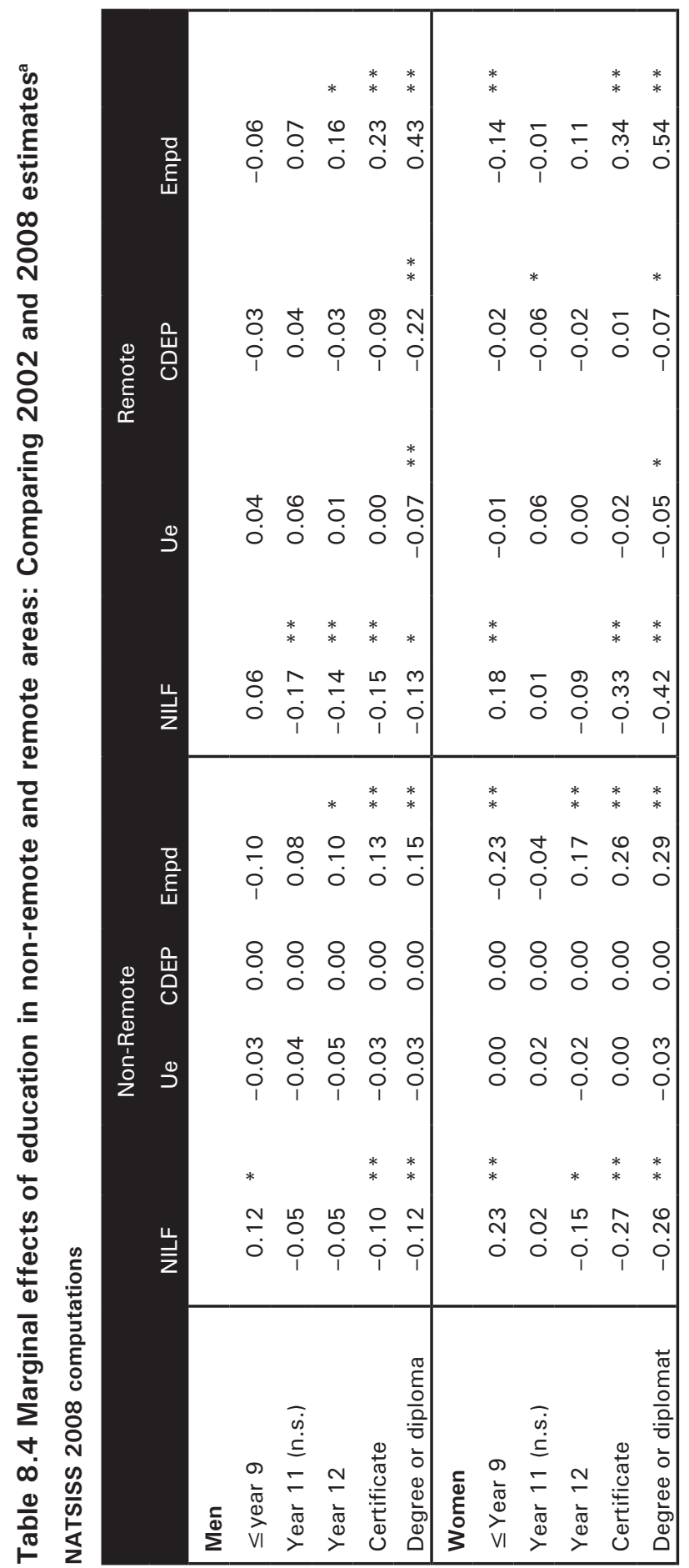




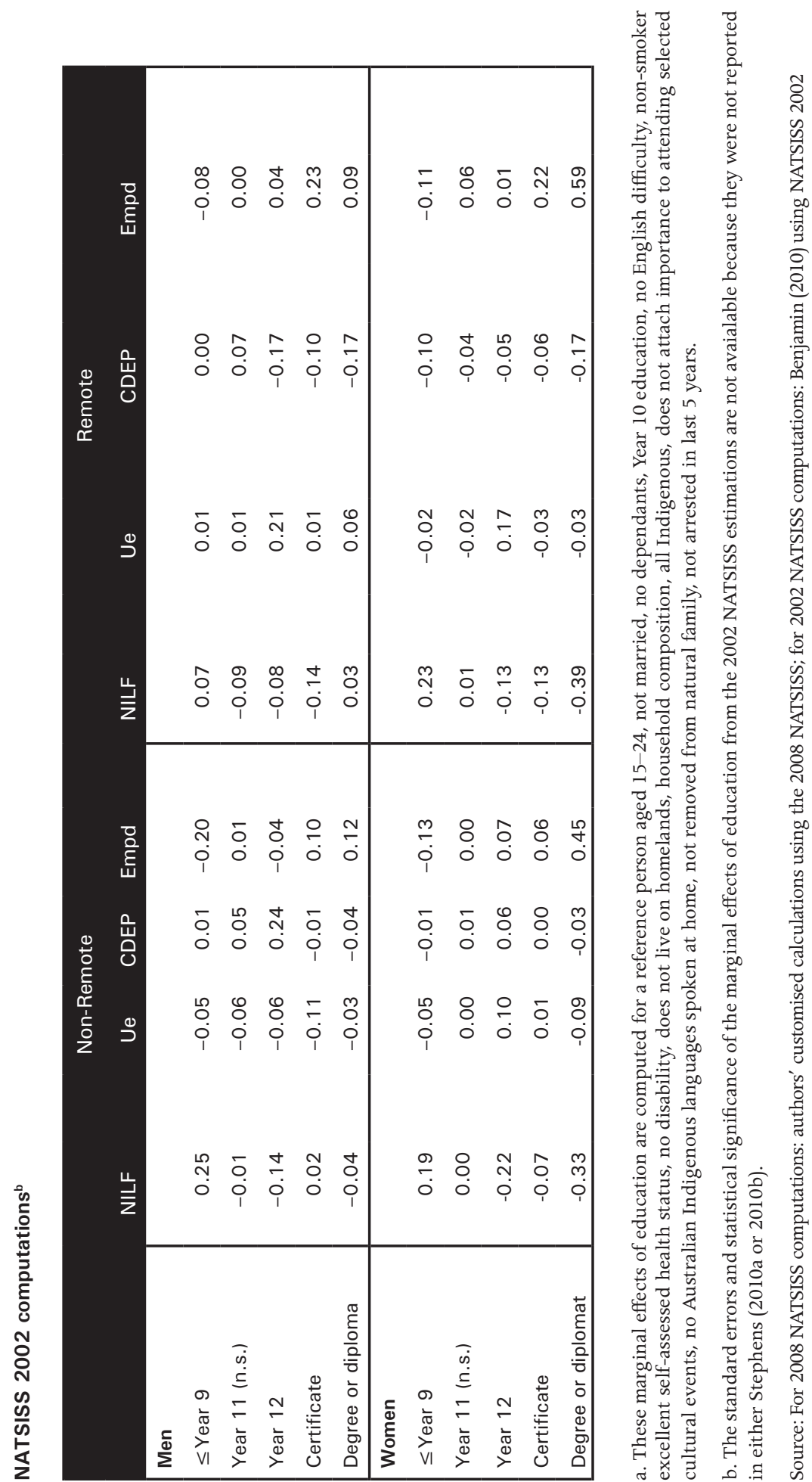




\section{Summary and conclusions}

This paper has summarised and modelled the factors behind the changes in Indigenous labour market status observed between the 2002 and 2008 NATSISS. Many of these changes were quite substantial with large numbers of working-age Indigenous men and women moving to regular employment, and dependence on CDEP schemes declining even in remote locations. Slightly more than 55 per cent of Indigenous working-age men have regular jobs while the corresponding ratio is about 42 per cent for working-age women.

The technical analyses in this chapter investigated the determinants of labour force status for working-age adults, using a multinomial logit regression approach that defined four labour force status categories - NILF, unemployed, CDEP participant and regular employment.

The estimated models utilised the wide range of demographic and socioeconomic variables collected in the 2008 NATSISS (i.e. education, health, culture, contact with the criminal justice system, etc.) to explain their effects on labour market status. The 'fit' of the estimated models is limited in that the proportion of the correct predictions made by the model is in the middle range of such models. ${ }^{15}$ But the results nevertheless highlight several key factors determining Indigenous employment and show that they are broadly similar to what has been reported for the general population, such as the age profile, health and education (Cai 2010; Laplagne, Glover and Shomos 2007).

The discussion of the results in the chapter, however, focused on the role of education and remote geographic location in explaining the differences in labour market status. Our overall estimation results were similar to what Stephens (2010a) had reported from the 2002 NATSISS, as well as with a recent contribution from the Productivity Commission (Savvas, Boulton and Jepsen 2011) using the 2008 NATSISS data.

Our results show that increasing educational attainment has been one of the key drivers of increasing Indigenous employment. There is a strong and near universal effect of higher levels of education in boosting the prospects for regular (non-CDEP) employment for working-age Indigenous men and women. Even small increases in educational achievements increase employment prospects by significant amounts. Completing Year 12 relative to only Year 10 increases the prospects of being employed by more than two times for Indigenous men and by about two times for Indigenous women. At higher levels of education, such as a degree or diploma, the boost to female employment prospects was usually stronger than for men.

Given these large effects of higher levels of educational attainment on the probability of being in regular employment, the overall increase in the education levels of Indigenous Australians account for some of large increase in the employment to

15 The pseudo $\mathrm{R}^{2}$ for our estimated models range from 0.18 to 0.27 ; but given we have run a logistics regression these psuedo $\mathrm{R}^{2}$ values are not clear measures of the proportion of the variance explained by the model. 
working-age population ratio observed between 2002 and 2008. In the Stephen (2010a) estimation sample from the 2002 NATSISS, about 35 per cent of all Indigenous working-age men and women had only a Year 9 (or below) qualification, and only 4.7 per cent had a degree or diploma. In our sample from the 2008 NATSISS, the proportion with Year 9 (or below) education has dropped to 27.6 per cent and the proportion with a degree or diploma has increased to 8.8 per cent (comparing our Appendix 8A Table 8A.1 with Table A.2 in Stephens 2010b).

Being in a remote location consistently increased the probability of being a CDEP participant, as expected, for both men and women. But living in a remote location by itself did not detract from the prospects for regular non-CDEP employment, controlling for other factors. We were not able to test separately for the effects of living in very remote locations compared to non-remote and just remote locations.

This chapter also estimated a more specific model with different impacts of the explanatory variables in remote and non-remote locations. There were substantial differences both in the set of variables that had significant effects and also in the magnitude of the marginal effects of these variables. One general result was that the marginal effects associated with higher levels of education were considerably higher in remote than in non-remote locations. Also the payoffs to higher levels of education in terms of increased probability of regular employment were higher for better educated women than for men.

The mechanisms driving these differential impacts of education in remote locations were not explored in this chapter; but if this result proves to be a robust finding it can have important implications for the design of regional specific labour market interventions and supporting educational policies.

In conclusion, it is worth noting that despite the unique nature of the design and coverage of the NATSISS and the detailed data it collects on a wide range of socioeconomic variables, it remains a cross-sectional survey. Hence identification of clear causal relationships between the explanatory variable used and the labour market states modelled will always be weak, given the many unobserved factors and differences in individual ability and circumstances of the selected sample. In addition our analyses did not control for any differences in labour market conditions arising from the labour demand side of the labour market. The geographic level of detail in the State by Remoteness version of the 2008 NATSISS data available on RADL is very limited, so that proxy variables to measure demand conditions at small regional levels cannot be implemented.

Increasing the level of regional disaggregation in future rounds of NATSISS and facilitating an easier concordance with other ABS geographic classifications, for which regional unemployment rates and other labour market data can be computed and linked, would be helpful for future analyses. This would not only facilitate developing proxy variables to control for changing labour demand considerations but also make it feasible to introduce smaller neighbourhood effects that may arise in determining the labour market outcomes of Indigenous working-age men and women. 


\section{Appendix 8A: Tables}

Table 8A.1 Summary statistics on regression variables for labour force status (means/proportions and standard deviations)

\begin{tabular}{|c|c|c|c|c|c|c|}
\hline \multirow[b]{2}{*}{ Variables } & \multicolumn{2}{|c|}{ All persons } & \multicolumn{2}{|c|}{ Men } & \multicolumn{2}{|c|}{ Women } \\
\hline & $\begin{array}{r}\text { Mean } \\
(\%)\end{array}$ & $\begin{array}{r}\text { Std Dev } \\
(\%)\end{array}$ & $\begin{array}{r}\text { Mean } \\
(\%)\end{array}$ & $\begin{array}{r}\text { Std Dev } \\
(\%)\end{array}$ & $\begin{array}{r}\text { Mean } \\
(\%)\end{array}$ & $\begin{array}{r}\text { Std Dev } \\
(\%)\end{array}$ \\
\hline Male & 43.0 & & 1 & & 0 & \\
\hline Remote location & 24.8 & 0.45 & 24.9 & 0.48 & 24.6 & 0.43 \\
\hline Age & & & & & & \\
\hline $15-24$ & 33.6 & 0.49 & 35.3 & 0.53 & 32.0 & 0.47 \\
\hline $25-34$ & 22.5 & 0.44 & 22.3 & 0.46 & 22.7 & 0.42 \\
\hline $35-44$ & 20.6 & 0.42 & 19.7 & 0.44 & 21.4 & 0.41 \\
\hline $45-54$ & 14.8 & 0.37 & 14.6 & 0.39 & 15.0 & 0.36 \\
\hline $55-64$ & 8.5 & 0.29 & 8.1 & 0.30 & 8.9 & 0.28 \\
\hline Married & 44.8 & 0.52 & 46.5 & 0.55 & 43.2 & 0.50 \\
\hline Number of dependents & & & & & & \\
\hline 0 dependants & 39.9 & 0.51 & 46.1 & 0.55 & 34.3 & 0.47 \\
\hline 1 & 21.0 & 0.43 & 18.9 & 0.43 & 22.8 & 0.42 \\
\hline $2-3$ & 28.2 & 0.47 & 25.6 & 0.48 & 30.6 & 0.46 \\
\hline $4 \&$ above & 10.9 & 0.33 & 9.3 & 0.32 & 12.4 & 0.33 \\
\hline Education & & & & & & \\
\hline Year 9 or below & 27.6 & 0.47 & 28.7 & 0.50 & 26.6 & 0.44 \\
\hline Year 10 & 23.4 & 0.44 & 24.1 & 0.47 & 22.7 & 0.42 \\
\hline Year 11 & 10.7 & 0.32 & 9.6 & 0.32 & 11.7 & 0.32 \\
\hline Year 12 & 12.4 & 0.35 & 12.6 & 0.36 & 12.3 & 0.33 \\
\hline Certificate & 17.1 & 0.39 & 18.2 & 0.42 & 16.2 & 0.37 \\
\hline Degree/Diploma & 8.8 & 0.30 & 6.8 & 0.28 & 10.6 & 0.31 \\
\hline Difficulty in English speaking & 3.1 & 0.18 & 3.5 & 0.20 & 2.8 & 0.16 \\
\hline Current smoker & 47.9 & 0.52 & 50.0 & 0.55 & 46.1 & 0.50 \\
\hline Self-assessed health status & & & & & & \\
\hline Very good & 44.7 & 0.52 & 47.3 & 0.55 & 42.3 & 0.49 \\
\hline Good & 34.5 & 0.50 & 32.7 & 0.52 & 36.3 & 0.48 \\
\hline Fair & 14.5 & 0.37 & 13.6 & 0.38 & 15.3 & 0.36 \\
\hline Poor & 6.3 & 0.25 & 6.4 & 0.27 & 6.1 & 0.24 \\
\hline Has disability & 48.3 & 0.52 & 47.4 & 0.55 & 49.2 & 0.50 \\
\hline Alcohol consumption & & & & & & \\
\hline High risk & 58.1 & 0.52 & 63.1 & 0.53 & 53.6 & 0.50 \\
\hline Low/medium risk & 6.5 & 0.26 & 9.4 & 0.32 & 3.9 & 0.19 \\
\hline Not consumed & 35.3 & 0.50 & 27.5 & 0.49 & 42.5 & 0.49 \\
\hline Live in homelands & 25.4 & 0.46 & 26.4 & 0.49 & 24.6 & 0.43 \\
\hline Mixed household & 39.1 & 0.51 & 42.3 & 0.54 & 36.1 & 0.48 \\
\hline Attends cultural events & 67.6 & 0.49 & 65.6 & 0.52 & 69.4 & 0.46 \\
\hline Indigenous language at home & 11.4 & 0.33 & 11.8 & 0.35 & 11.2 & 0.32 \\
\hline Removed from natural family & 7.8 & 0.28 & 7.5 & 0.29 & 8.1 & 0.27 \\
\hline Queensland only: Torres Strait Islander & 5.9 & 0.25 & 6.3 & 0.27 & 5.4 & 0.23 \\
\hline Arrested in last 5 years & 15.6 & 0.38 & 22.8 & 0.46 & 9.1 & 0.29 \\
\hline Sample N & & 085 & & 58 & & 027 \\
\hline
\end{tabular}

Source: Authors' customised calculations using the 2008 NATSISS (accessed via RADL) 
8. What are the factors determining Indigenous labour market outcomes?

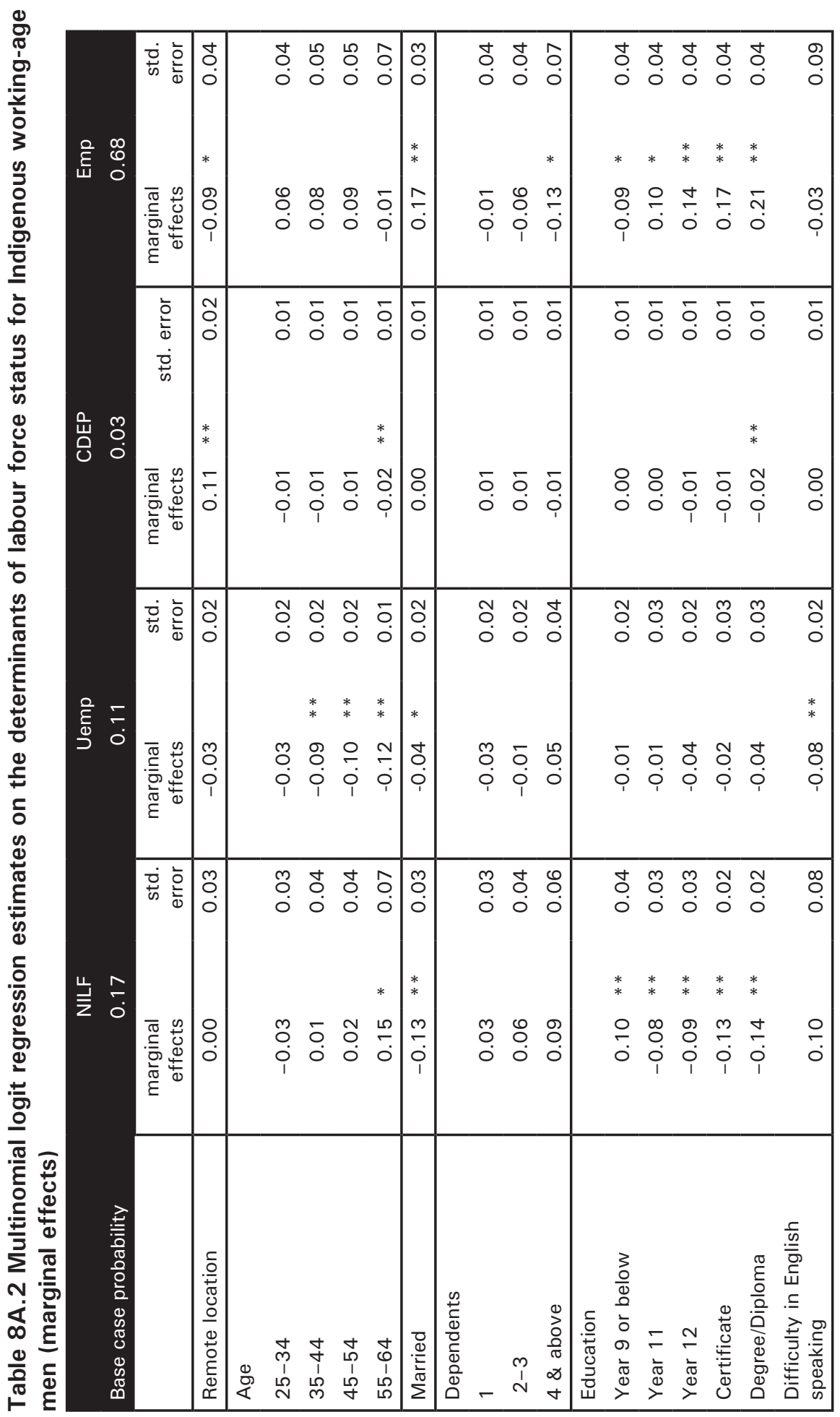




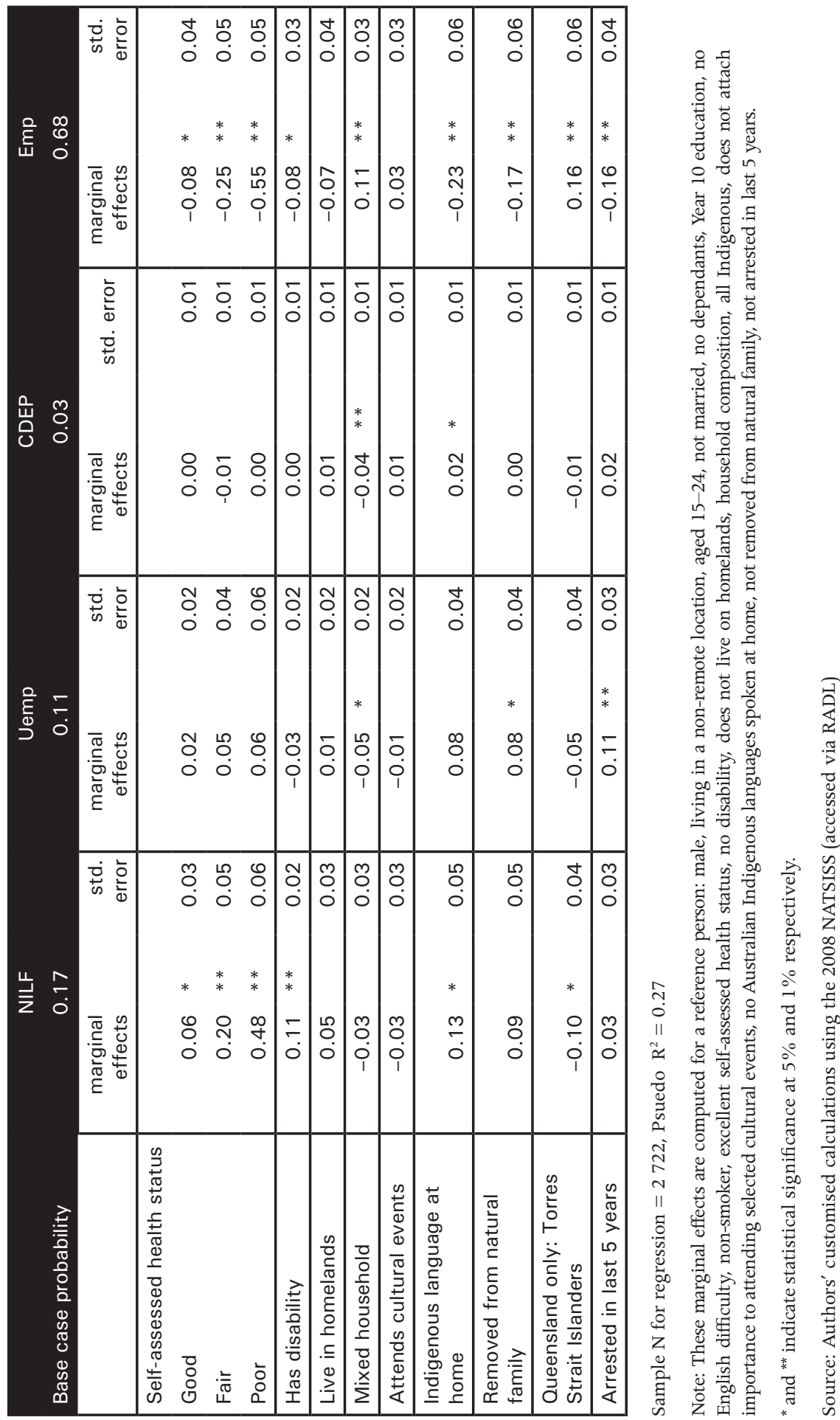


8. What are the factors determining Indigenous labour market outcomes?

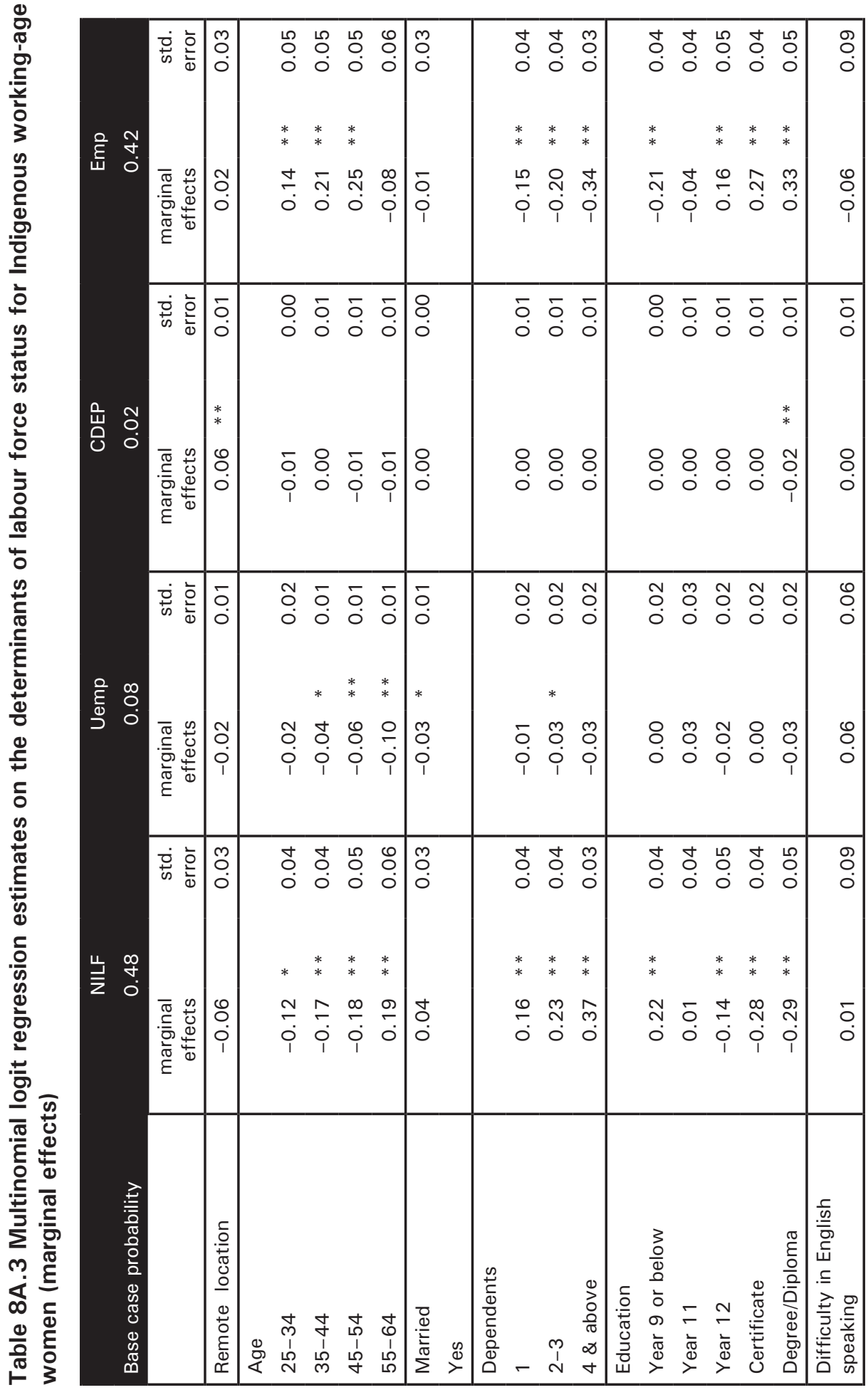




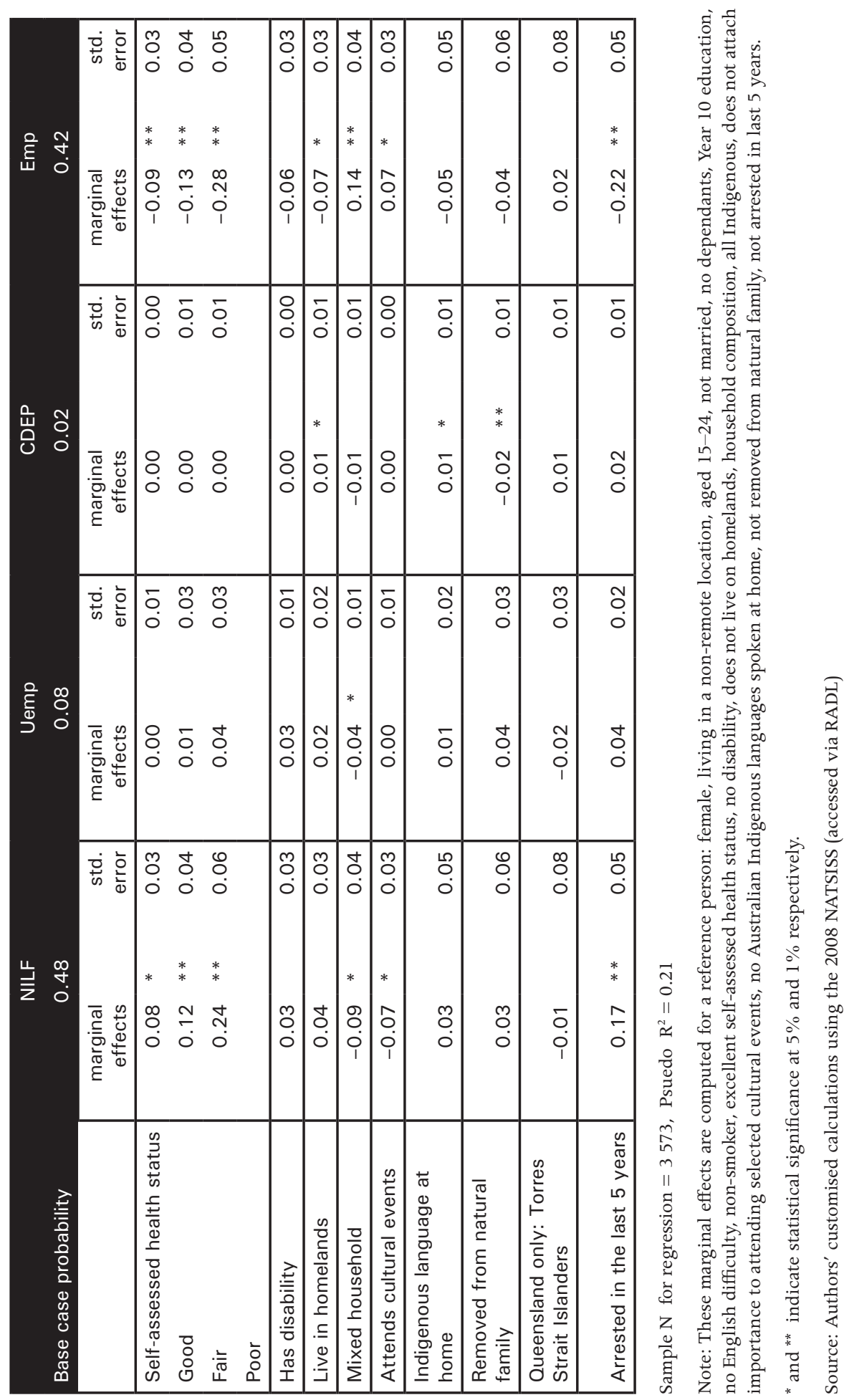




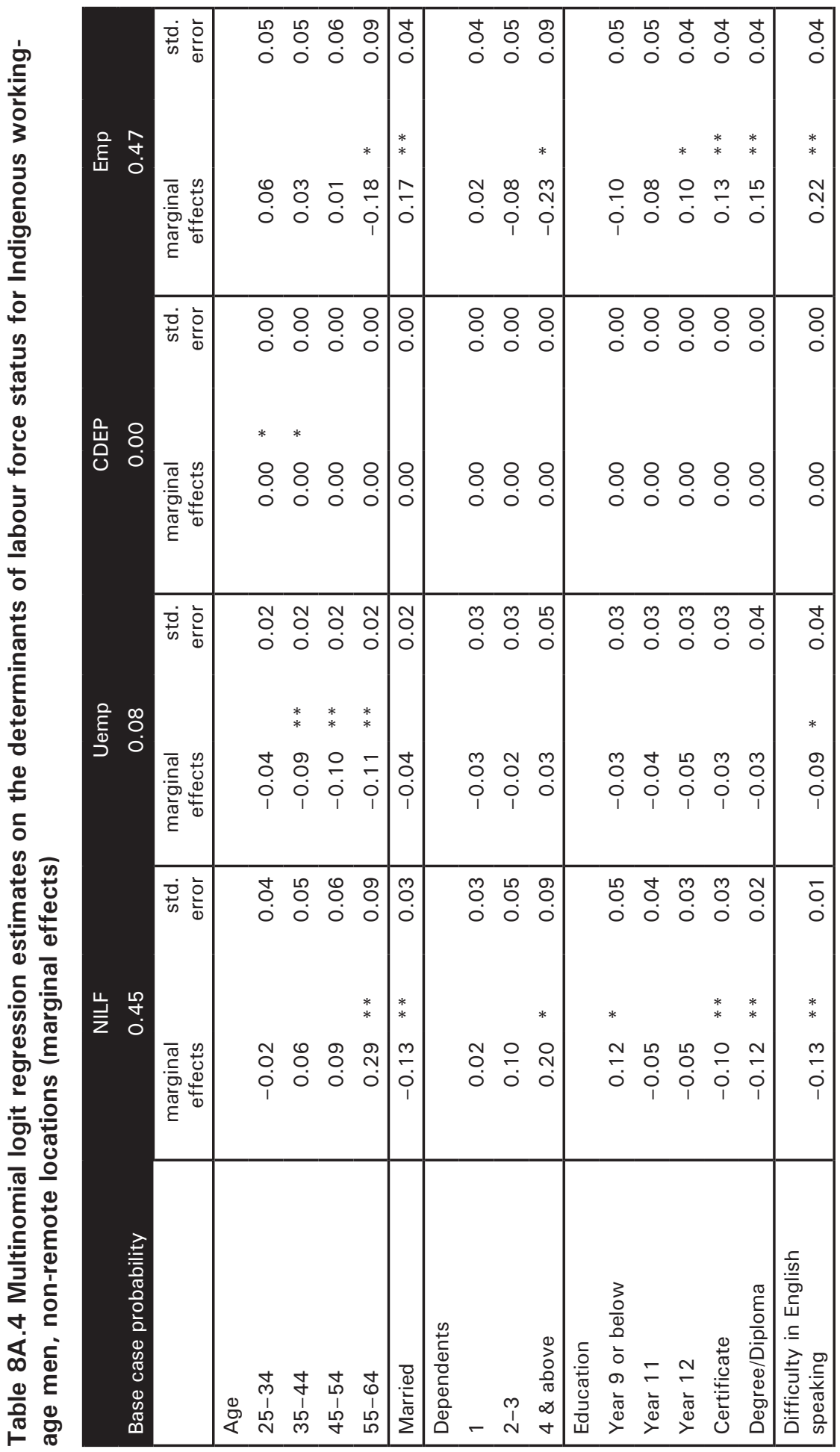




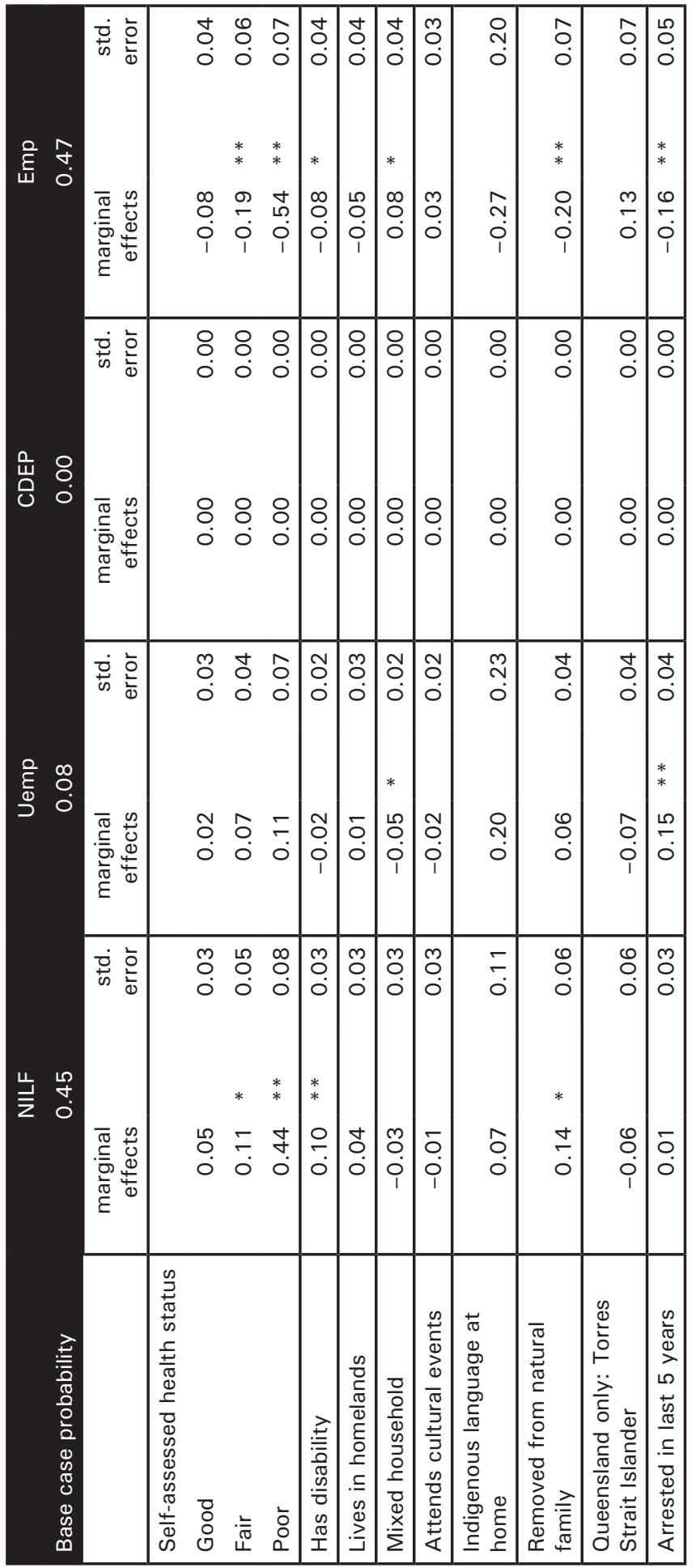


8. What are the factors determining Indigenous labour market outcomes?

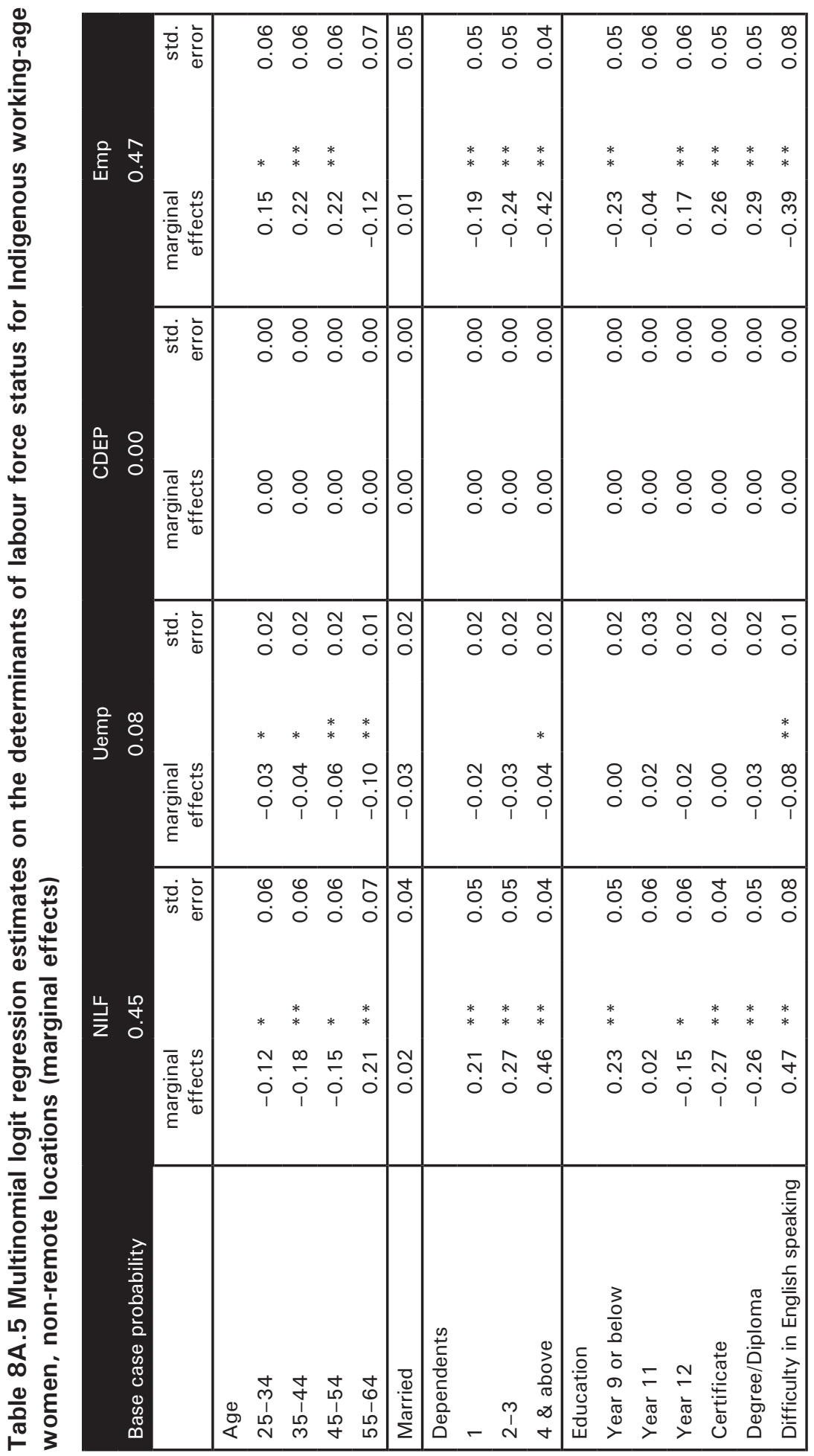




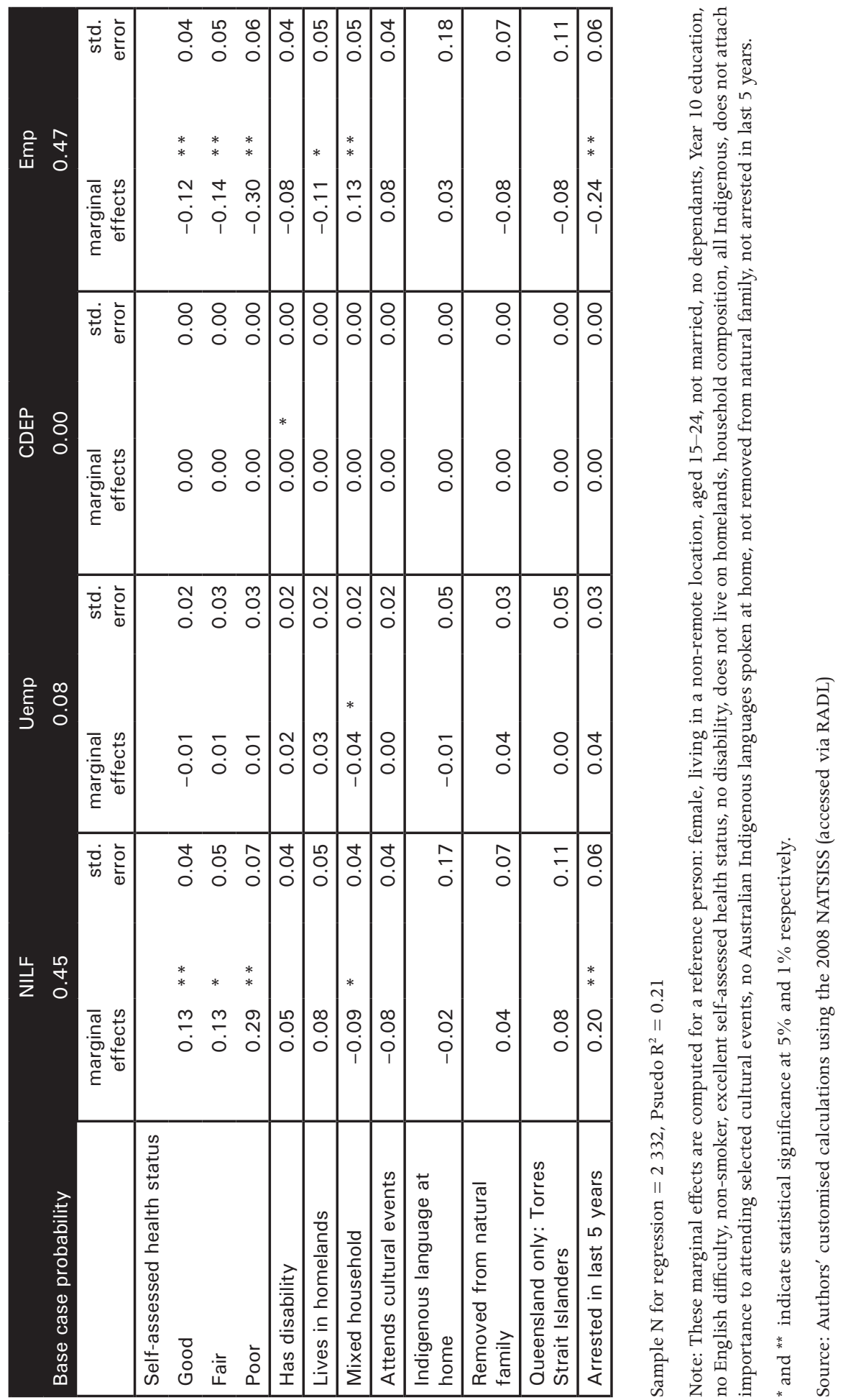




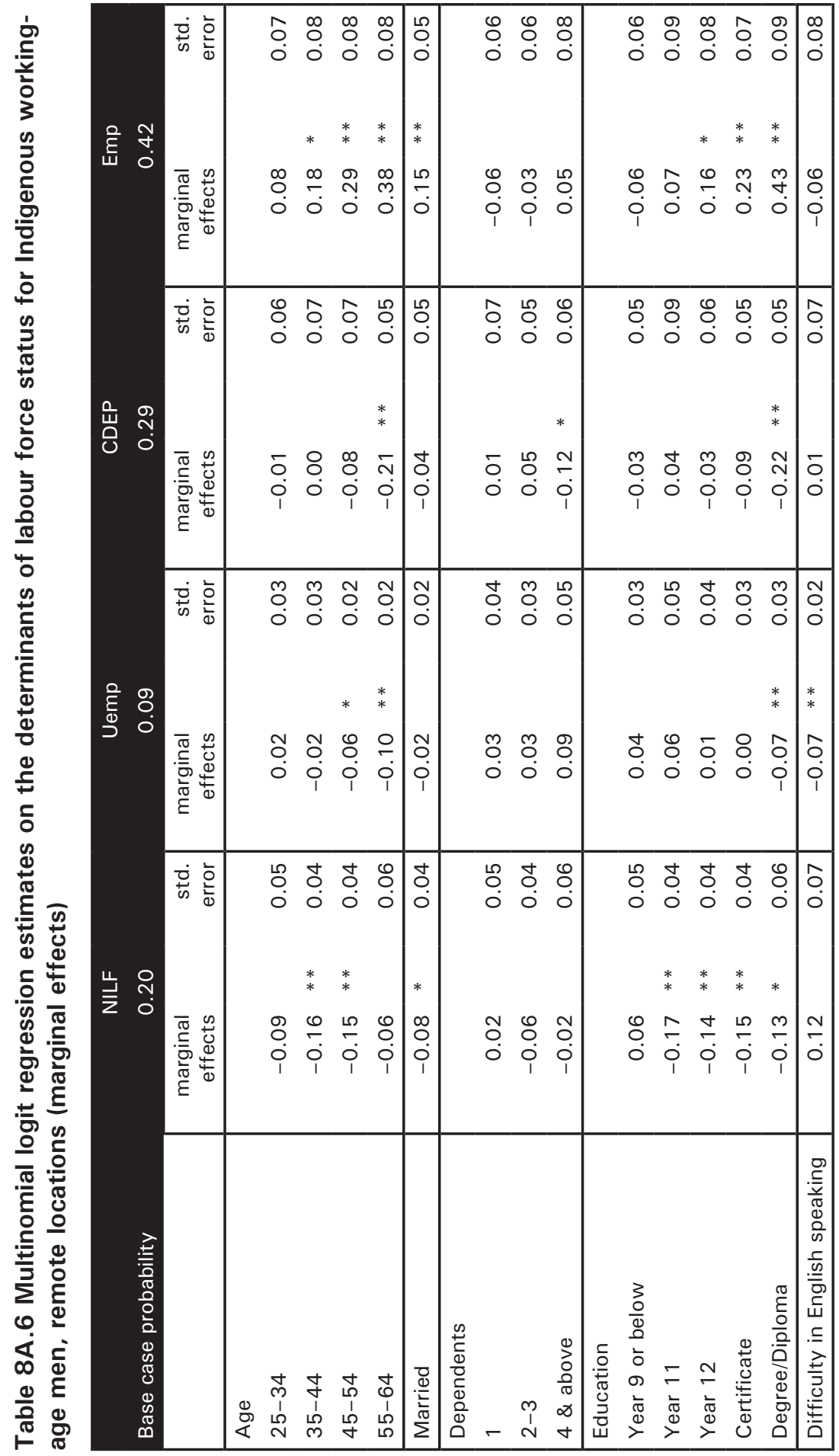




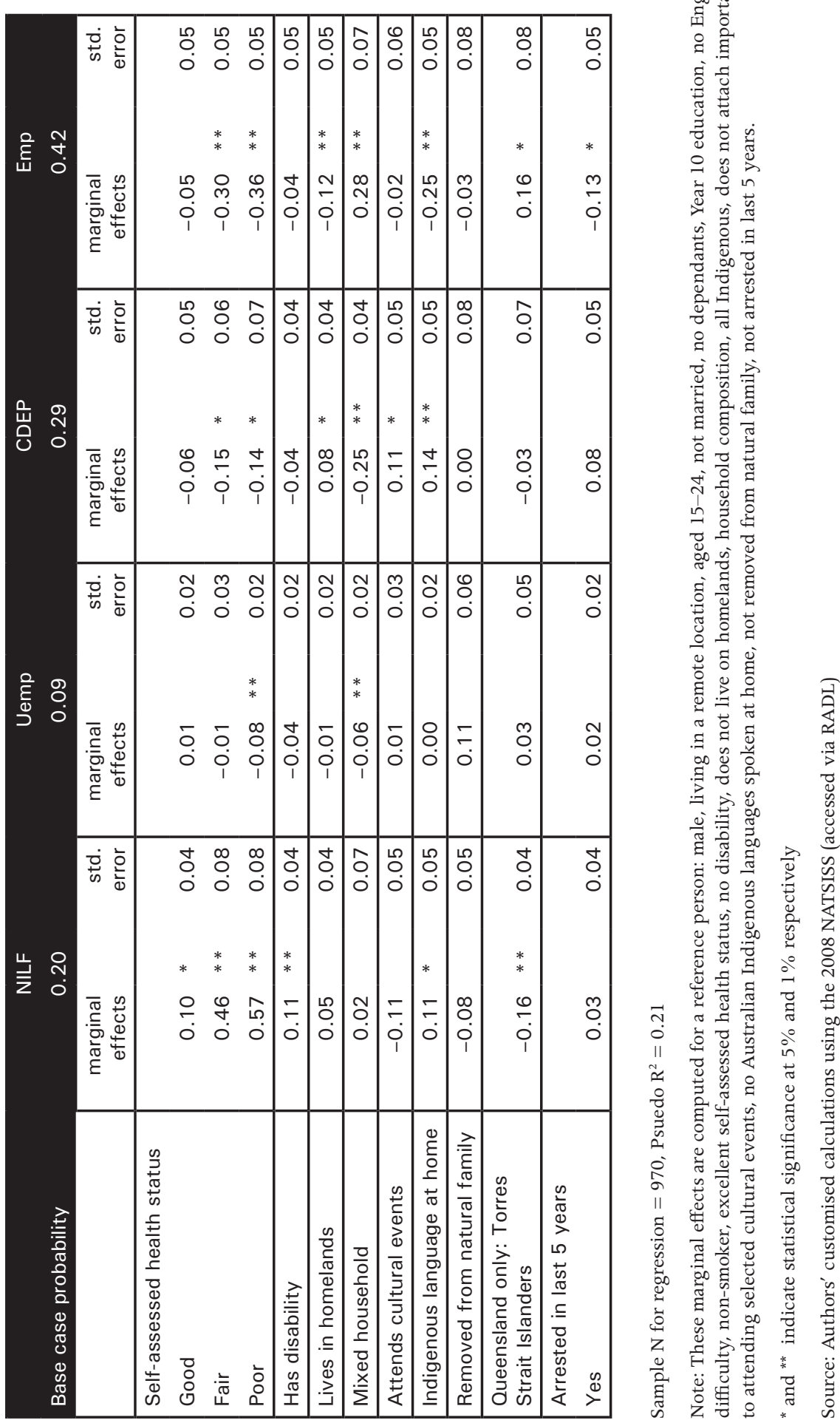




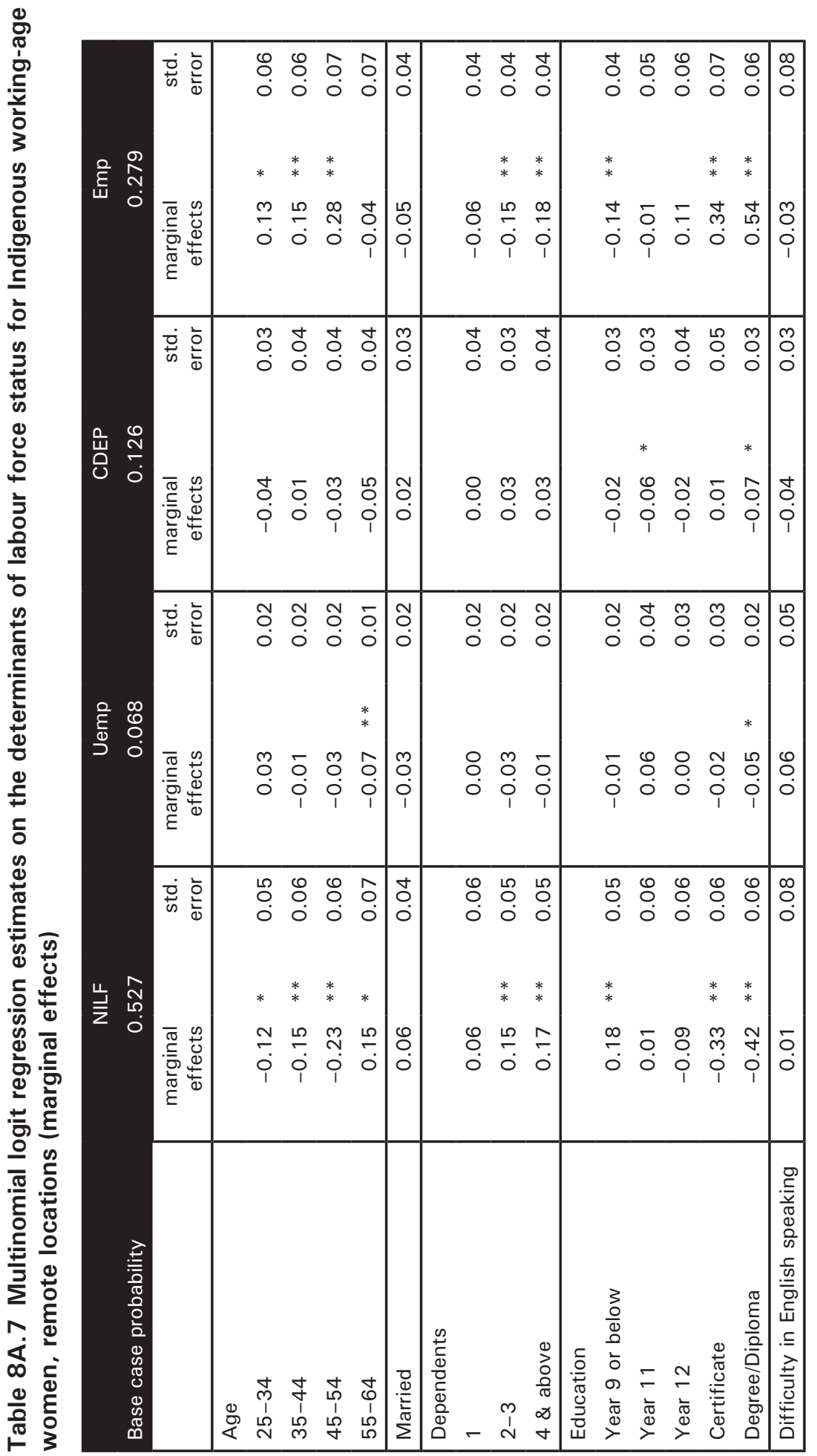




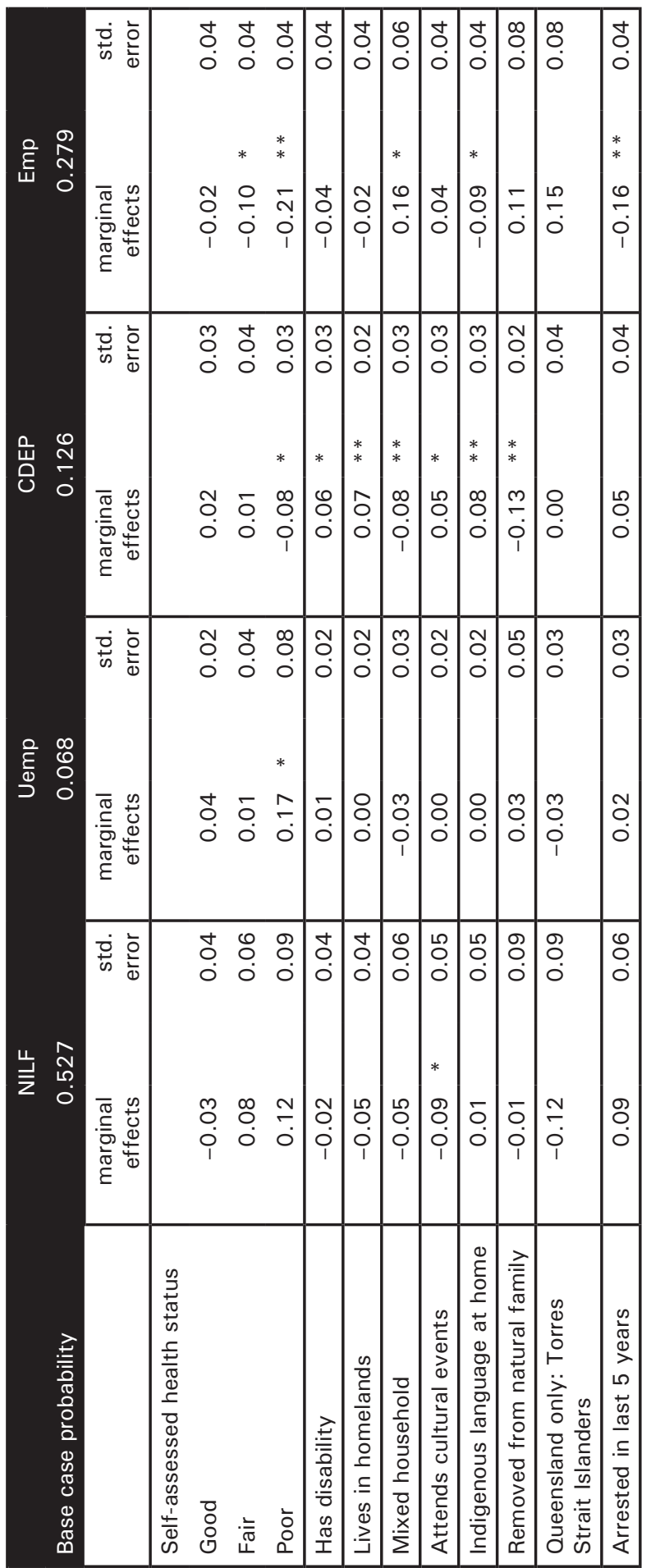

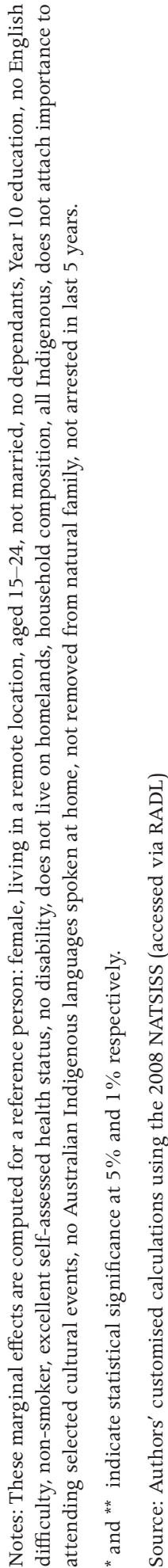




\section{Acknowledgements}

The views expressed in this chapter are the personal views of the authors and should not be attributed to the Australian Government Department of Families, Housing, Community Services and Indigenous Affairs or to the Australian Government. The chapter uses data from the NATSISS State by Remoteness 2008 Expanded Reissue 1 CURF (and the corresponding file for the 2002 NATSISS) accessed via the Remote Access Data Laboratory (RADL). We are grateful to the RADL team at the Australian Bureau of Statistics for their help in using RADL and in programming support. Comments provided by Matthew James from FaHCSIA and Matthew Gray (who was Discussant on the earlier draft of this chapter presented at the conference organised by CAEPR on 11-12 April 2011) are also gratefully acknowledged. All errors and omissions, however, are our own.

\section{References}

Australian Bureau of Statistics (ABS) 2004). National Aboriginal and Torres Strait Islander Social Survey 2002, cat. no. 4714.0, ABS, Canberra.

2006. Labour Force Characteristics of Aboriginal and Torres Strait Islander Australians: Experimental Estimates from the Labour Force Survey, cat.no. 6287.0, ABS, Canberra.

2009. National Aboriginal and Torres Strait Islander Social Survey 2008, cat. no. 4714.0, ABS, Canberra.

Australian Institute of Health and Welfare (AIHW) 2011. Aboriginal and Torres Strait Islander Health Performance Framework 2010: detailed analyses; 14/9/2011 edition, tier 2 section 17: Indigenous people with access to their traditional lands, cat. no. IHW 53, AIHW, Canberra.

Biddle, N. and Hunter, B. H. 2006. 'Selected Methodological Issues for Analysis of the 2002 NATSISS', in B. H. Hunter (ed.), Assessing Recent Evidence on Indigenous Socioeconomic Outcomes: A Focus on the 2002 NATSISS, CAEPR Research Monograph No. 26, ANU E Press, Canberra.

and Yap, M. 2010. Demographic and Socioeconomic Outcomes Across the Indigenous Australian Life Course: Evidence from the 2006 Census, CAEPR Research Monograph No. 31, ANU E Press, Canberra. 
Cai, L. 2010. 'The relationship between health and labour force participation: Evidence from a panel data simultaneous equation model', Labour Economics, 17 (1): 77-90.

Daly, A. E. 1995. Aboriginal and Torres Strait Islander People in the Australian Labour Market, cat. no. 6253.0, ABS, Canberra.

Gray, M. C. and Chapman, B. 2006. 'Labour market issues' in B. H. Hunter (ed.), Assessing Recent Evidence on Indigenous Socioeconomic Outcomes: A Focus on the 2002 NATSISS, CAEPR Research Monograph No. 26, ANU E Press, Canberra.

and Hunter, B. H. 2005. 'The labour market dynamics of Indigenous Australians', Journal of Sociology, 41: 389-408.

and - 2011. 'Changes in Indigenous labour force status: Establishing employment as a social norm', CAEPR Topical Issue No. 7/2011, CAEPR, ANU, Canberra.

Hunter, B. H. 2004. Indigenous Australians in the Contemporary Labour Market, cat. no. 2052.0, ABS, Canberra.

and Gray, M. 2001. 'Indigenous labour force status re-visited: Factors associated with the discouraged worker phenomenon', Australian Journal of Labour Economics, 4 (2): 111-33.

Laplagne, P., Glover, M. and Shomos, A. 2007. 'Effects of health and education on labour force participation', Productivity Commission Staff Working Paper, Melbourne.

Savvas, A., Boulton, C. and Jepsen, E. 2011. 'Influences on Indigenous labour market outcomes', Productivity Commission Staff Working Paper, Melbourne.

Steering Committee for the Review of Government Service Provision (SCRGSP) 2011. Overcoming Indigenous Disadvantage: Key Indicators 2011, Productivity Commission, Canberra.

Stephens, B. J. 2010a. 'The determinants of labour force status among Indigenous Australians', Australian Journal of Labour Economics, 13 (3): 287-312.

2010b. 'The determinants of labour force status among Indigenous Australians', University of Western Australia Economics Discussion Paper 10.11 . 